\title{
The South Atlantic Convergence Zone: Intensity, Form, Persistence, and Relationships with Intraseasonal to Interannual Activity and Extreme Rainfall
}

\author{
Leila M. V. Carvalho \\ Department of Atmospheric Sciences, Institute of Astronomy, Geophysics and Atmospheric Sciences, University of São Paulo, \\ São Paulo, Brazil \\ CHARles JONES \\ Institute for Computational Earth System Science, University of California, Santa Barbara, Santa Barbara, California \\ BRANT LIEBMANN \\ NOAA-CIRES Climate Diagnostics Center, Boulder, Colorado
}

(Manuscript received 12 September 2002, in final form 7 July 2003)

ABSTRACT

\begin{abstract}
The characteristics of intensity, geographical location, and persistence of the South Atlantic convergence zone (SACZ) during the austral summer are investigated. Intensity and spatial features of the SACZ are identified by performing a factor analysis of structural properties of outgoing longwave radiation (OLR) data. The first two leading factors explain $65 \%$ of the total variance of structural properties and characterize the SACZ according to intensity and location (oceanic versus continental). An index is constructed based on the magnitude of the factor scores to identify intense (weak) and oceanic (continental) SACZ. The intense SACZ category is associated with negative OLR anomalies over a large area of tropical South America, extending from the western Amazon to the Atlantic Ocean. The weak SACZ category is observed with positive OLR anomalies over tropical South America and negative OLR anomalies over southeastern South America. Oceanic and continental aspects of the SACZ are related to a midlatitude wave train pattern. The Madden-Julian oscillation (MJO) modulates intense SACZ events with persistence longer than 3 days. Interannual variability of persistent events indicates that the ratio of oceanic to continental SACZ as well as their frequency depends on the phase of El Niño-Southern Oscillation (ENSO). Occurrence of extreme rainfall in Brazil is discussed in the context of variations in the SACZ and MJO. Intense (weak) SACZ increases (decreases) the 95th daily rainfall percentile over centraleastern Brazil compared to the climatology. Oceanic (continental) SACZ increases (decreases) the 95th daily rainfall percentile over southeastern Brazil. The MJO phase characterized by suppression of convective activity over Indonesia and enhancement over the central Pacific increases the 95th daily rainfall percentile over northnortheastern Brazil, whereas opposite features are observed for the phase of the MJO characterized by the enhancement of convection over Indonesia and suppression over the central Pacific.
\end{abstract}

\section{Introduction}

The South Atlantic convergence zone (SACZ) is an important climatological feature of the austral summer in South America. The SACZ has been subjectively defined as an elongated convective band typically originating in the Amazon basin, extending toward southeast Brazil and protruding into the southeastern subtropical Atlantic Ocean (Kodama 1992, 1993; Satyamurti et al. 1998; Carvalho et al. 2002). The SACZ and convective activity in the Amazon basin are the main components

Corresponding author address: Dr. Leila M. V. Carvalho, Institute of Astronomy, Geophysics and Atmospheric Sciences, University of São Paulo, R. do Matão, 1226, Cidade Universitária, São Paulo, SP 05508-900, Brazil.

E-mail: leila@model.iag.usp.br of the South American monsoon system (SAMS) (Jones and Carvalho 2002).

A striking characteristic of the precipitation regimes in South America is the wide range of time and space scales of variability. While convection in the Amazon basin exhibits strong diurnal and seasonal changes, intraseasonal (10-90 days) variations are more pronounced over eastern tropical and subtropical South America (Kiladis and Weickmann 1992; Liebmann et al. 1999; Nogués-Paegle and Mo 1997; Nogués-Paegle et al. 2000). Moreover, Jones and Carvalho (2002) demonstrated that intraseasonal variations in DecemberFebruary low-level wind regimes over tropical South America are linked to breaks and active phases of SAMS. On the other hand, on longer time scales, interannual variations associated with the El Niño-South- 
ern Oscillation (ENSO) are also detected over parts of South America including the SACZ (Ropelewski and Halpert 1987; Grimm 2003; Robertson and Mechoso 2000; Liebmann et al. 2001; Carvalho et al. 2002).

Although those previous studies have considerably improved the understanding of the relationships between low-frequency modes such as the MJO (Madden and Julian 1994) and ENSO, and convective activity over tropical South America, some key questions need to be further investigated. Past studies investigated the variability of the SACZ using a combination of filtered data [outgoing longwave radiation (OLR)], empirical orthogonal function (EOF) analysis and composites to examine the spatial variability of the signal (Liebmann et al. 1999; Lenters and Cook 1999; Nogués-Paegle and Mo 1997; Nogués-Paegle et al. 2000). A drawback of these techniques is that a large fraction of the total variability of convective activity may not be incorporated in the composite categories. For instance, it is well known in the meteorological forecasting community that the SACZ can exhibit substantial changes in its geographical extension. Satellite images oftentimes show that the SACZ can extend from the Amazon toward the subtropical Atlantic Ocean, whereas in other situations the SACZ merely extends over southeast Brazil. Similarly, quite often the intense convective activity in the SACZ seems to not persist, while it may last longer in other situations. Although operational forecasters subjectively know these variations, some basic questions need to be objectively addressed: Are there distinct differences in the SACZ intensity (intense vs weak) and geographical extension (continental vs oceanic)? What is the frequency distribution of the SACZ persistence? Does the MJO modulate the SACZ intensity, persistence, and geographical location? Are there systematic changes in the SACZ associated with ENSO? Additionally, given that the SACZ and MJO play a fundamental role in the precipitation variability in Brazil: what are the relationships among SACZ, MJO, and the occurrence of extreme rainfall events?

In a recent study, Carvalho et al. (2002) developed a methodology to characterize structural properties of the SACZ and investigated the influence of SACZ characteristics in modulating daily extreme rainfall over São Paulo state in Brazil. They showed that the SACZ intensity and its extent to the Atlantic Ocean determine the spatial distribution of extremes in São Paulo. The present paper has several objectives. We first expand the methodology to characterize the SACZ according to intensity, location, and persistence (section 3). Intraseasonal variations in convective activity and largescale circulation in different SACZ categories are discussed next (section 4). The statistical properties of the SACZ persistence are examined (section 5), followed by an analysis of interannual variations in SACZ categories (section 6). The modulation by the MJO of the SACZ is then assessed (section 7). Last, the occurrences of extreme rainfall in Brazil are considered in the context of SACZ and MJO variations (section 8).

\section{Data}

This study focuses on the austral summer, which is defined here as from December to February (DJF). In order to characterize large-scale aspects of tropical convection during DJF, we use daily OLR (1979-2000) with $2.5^{\circ}$ horizontal resolution (Liebmann and Smith 1996). The large-scale atmospheric circulation is described in this study with National Centers for Environmental Prediction-National Center for Atmospheric Research (NCEP-NCAR) reanalysis (Kalnay et al. 1996). The departure from the seasonal cycle is obtained by subtracting the daily DJF ORL climatology (hereafter referred to as anomalies). The seasonal cycle was smoothed before subtracting the climatology from the daily time series. The relationships with intraseasonal variations are examined by computing anomalies with a Lanczos bandpass filter with cutoff periods of 10 and 90 days and 151 weights (Duchon 1979; Jones et al. 1998) (henceforth called intraseasonal anomalies). A dense network of stations in Brazil was used to construct daily gridded precipitation maps. The original station data were obtained from ANEEL (Agência Nacional de Energia Elétrica) and meteorological agencies in the states of Ceará, São Paulo, and Paraná. South of $15^{\circ} \mathrm{S}$, there are about 2500 stations with an average record of $16 \mathrm{yr}$ (1979-98). On average, 5\% of missing data is present in years with data. The station data were averaged into $2^{\circ}$ (lat) $\times 2^{\circ}$ (lon) squares, with the assumption that there is sufficient station density such that an occasional missing datum will not affect the gridpoint average.

\section{SACZ characteristics}

We begin the discussion reviewing some key features that form the basis of our methodology to investigate the variability of the SACZ. Figure 1 (top) shows the mean daily rainfall and $850-\mathrm{hPa}$ winds, which indicates maximum precipitation in the Amazon basin extending toward southeast Brazil. Carvalho et al. (2002) have shown that OLR features $\leq 200 \mathrm{~W} \mathrm{~m}^{-2}$ are closely related to rainfall spatial patterns. The SACZ has been generically described as the region with high variability of convective activity (Fig. 1, bottom) during summertime in eastern South America (Liebmann et al. 1999; Zhou and Lau 1998). In order to be consistent with this subjective definition, the three areas indicated in Fig. 1 (bottom, dashed lines) enclose the regions with maximum convective activity and minimum subseasonal variance (Amazon), and maximum subseasonal variance (coastal and ocean). These regions are used to examine variations in the SACZ strength as well as its geographical location (i.e., continental versus oceanic). To accomplish this, we construct a daily index based on OLR 
(a)

\section{DJF Mean Daily Rain and Winds (850 hPa)}

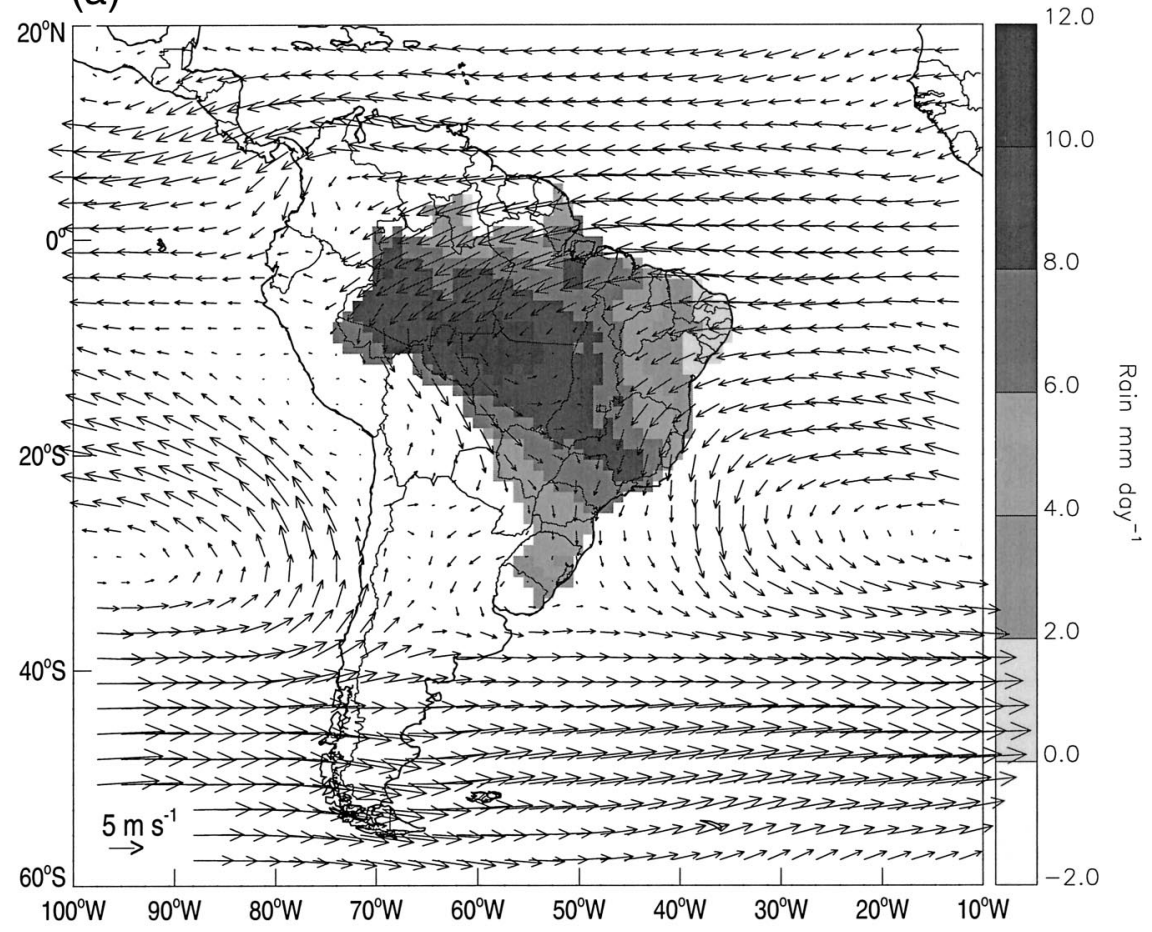

(b)

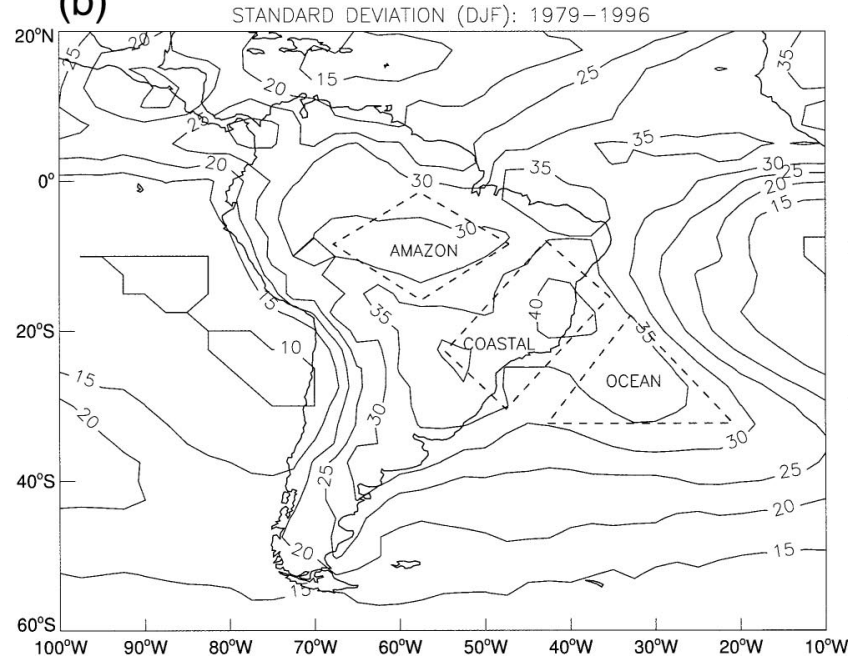

FIG. 1. (a) Gridded mean daily precipitation ( $2^{\circ}$ lat/lon) obtained from stations over Brazil and low-level winds $(850 \mathrm{hPa})$ from reanalysis during summertime (DJF). (b) DJF OLR standard deviation $\left(\mathrm{W} \mathrm{m}^{-2}\right)$. Areas indicated with dotted lines are located over regions with maximum subseasonal standard deviation (coastal and ocean), and maximum subseasonal convective activity (Amazon). See text for more details.

structural properties. The methodology to obtain this index is discussed in detail in Carvalho et al. (2002) and summarized here as follows. First, spatial and structural characteristics of daily large-scale deep convective activity in the SACZ are investigated by identifying contiguous (i.e., connected grid points) regions of OLR $\leq 200 \mathrm{~W} \mathrm{~m}^{-2}$. Only those contiguous regions that intercept the coastal area are selected (hereafter $\mathrm{OLR}_{200}$ ). We identified 1750 days with OLR $_{200}$ during DJF 19792000. Next, the maximum spatial correlation tracking technique (MASCOTTE) algorithm (Carvalho and
Jones 2001) is used to examine spatial and temporal characteristics of selected $\mathrm{OLR}_{200}$ cases. Figure 2, which illustrates an example of an OLR $_{200}$ map, shows the properties that were determined. They are: area (Area), eccentricity (Ecc), minimum OLR (OLRmin), fraction of OLR ${ }_{200}$ with OLRmin (\%OLRmin), and OLR spatial variance (VarOLR). The parameter \%OLRmin was defined as the ratio between the number of grid points with OLRmin to the number of grid points with OLR ${ }_{200}$. An ellipse is fitted to the contiguous $\mathrm{OLR}_{200}$ region and is only used to determine the eccentricity, defined as the 


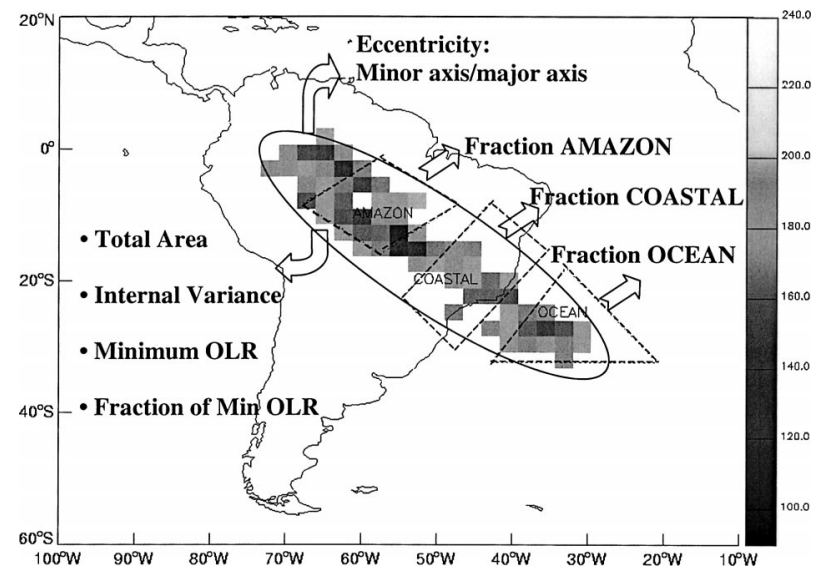

FIG. 2. Example of $\mathrm{OLR}_{200}$ properties obtained with the MASCOTTE algorithm.

ratio between the minor axis and major axis. Therefore large (small) values of Ecc imply circular (linear) shapes. Since the SACZ exhibits significant spatial variability, $\mathrm{OLR}_{200}$ features can oftentimes extend in a northwest-southeast configuration and intercept the Amazon and/or ocean regions. To keep track of this variability, the fraction of $\mathrm{OLR}_{200}$ in each of the three regions was computed (\%Amazon, \%Coastal, and $\%$ Ocean). Note that large $\mathrm{OLR}_{200}$ features can have part of their area outside the coastal domain and, therefore, small \%Coastal values. The opposite situation holds when $\mathrm{OLR}_{200}$ has a small area and is entirely contained in the coastal area. The elongated and oceanic characteristics illustrated in Fig. 2 are not the only possible spatial configurations of the SACZ deep convection. Spatial configurations vary substantially during the summer.

The categorization of large-scale convective activity in the SACZ was performed by considering the OLR ${ }_{200}$ structural properties discussed above. With these properties, it is possible to distinguish patterns of OLR ${ }_{200}$ by incorporating both extent (Area) and intensity of convective activity (OLRmin, \%OLRmin, VarOLR). The Ecc parameter provides information about the roundness of the OLR ${ }_{200}$ features, which in combination with \%Amazon, \%Coastal, and \%Ocean, allows the discrimination of events when the SACZ is continental or oceanic. Subsequently, factor analysis was applied to objectively determine categories of SACZ convective activity according to its intensity and structural properties.

As in Carvalho et al. (2002), the input data for the factor analysis are time series represented by the matrix $M_{m \times p}$, in which the elements are normalized $\mathrm{OLR}_{200}$ structural properties. The number of variables $p$ is equal to 8 (Area, Ecc, OLRmin, \%OLRmin, VarOLR, \%Amazon, \%Coastal, and \%Ocean) and the number of events $m$ is equal to 1750 (number of case studies with $\left.\mathrm{OLR}_{200}\right)$. Two factors are retained with eigenvalues $\lambda$ $>$ 1.0. A normal varimax rotation is applied (Jackson 1991) to improve the maximization of the variance explained by each factor. The factor loadings, eigenvalues, and respective total variance explained by each factor are shown in Table 1 . They indicate that factor 1 , which explains about $\sim 46 \%$ of the total variance of structural properties, has high loading associated with Area and VarOLR and is negatively correlated with OLRmin, $\%$ OLRmin, and \%Coastal. Negative correlation between Area and \%Coastal indicates that extensive OLR ${ }_{200}$ have large fractions of their area outside the coastal domain. OLRmin, with same sign as \%OLRmin and opposite to Area indicates that the larger $\mathrm{OLR}_{200}$, the lower OLRmin. This implies that a region with very low OLRmin does not cover a large fraction of the OLR ${ }_{200}$, which increases the internal OLR variance (OLRmin and \%OLRmin with opposite signs to VarOLR). The opposite situation is observed when the SACZ is weak. Factor 2 explains $\sim 19 \%$ of the total variance of structural properties and shows large loading on Ecc and \%OCEAN with opposite sign (negatively correlated). Consequently, factor 1 is related to intensity whereas factor 2 is associated with the shape of deep convection in the SACZ. The Varimax rotation used here resulted in a decrease (increase) of the loading on \%Amazon (\% coastal) in factor 1 , which was convenient to enhance the role of convective features over the coastal area rather than over the Amazon area.

TABLE 1. Factor loadings (varimax normalized) for $N=1576$ (DJF) occurrences of OLR ${ }_{200}$ intercepting the coastal area. The eigenvalues $\lambda_{\mathrm{j}}$ with the corresponding $\delta \lambda$ uncertainty (North et al. 1982) indicate that $\lambda_{1}$ and $\lambda_{2}$ are independent. Loadings $>0.70$ are in bold font.

\begin{tabular}{|c|c|c|c|c|}
\hline Variable & Factor 1 & Interpretation & Factor 2 & Interpretation \\
\hline Area & -0.82 & Correspondence between & -0.03 & High weights on Ecc and \\
\hline Ecc & 0.01 & spatial extent and intensity & 0.77 & $\%$ Ocean with opposite sign \\
\hline OLRmin & 0.89 & of large-scale convection & -0.06 & associate this factor with \\
\hline$\%$ OLRmin & 0.87 & in the SACZ: & 0.01 & elongation of the SACZ to \\
\hline VarOLR & -0.70 & & 0.04 & the Atlantic Ocean: \\
\hline$\%$ Coastal & 0.82 & & 0.07 & \\
\hline$\%$ Amazon & -0.57 & Factor $1>0$ : weak & 0.42 & Factor $2>0$ continental \\
\hline$\%$ Ocean & 0.00 & Factor $1<0$ : intense & $-\mathbf{0 . 8 3}$ & Factor $2<0$ oceanic \\
\hline$\lambda \pm \delta \lambda$ & & $3.72 \pm 0.13$ & & $1.48 \pm 0.04$ \\
\hline Expl. variance & & 0.46 & & 0.19 \\
\hline
\end{tabular}


Table 1 indicates that negative (positive) factor 1 scores are related to SACZ with intense (weak) convective activity and large (small) extension. Analogously, positive (negative) factor 2 scores can be linked to oceanic (continental) aspects of the $\mathrm{OLR}_{200}$. Since the objective of our methodology is to use these two factors as indexes to characterize SACZ occurrences, we have defined four categories as follows: intense (factor $1 \leq 25$ th percentile), weak (factor $1 \geq 75$ th percentile), oceanic (factor $2 \leq 25$ th percentile), and continental (factor $2 \geq 75$ th percentile). Intense and weak categories are, therefore, defined regardless of SACZ geographic aspects, whereas oceanic and continental categories are determined regardless of SACZ intensity. The reason for using percentiles to find typical events in each category is because the factor distributions are skewed (Carvalho et al. 2002). The total number of days in each category is equal to 438 , such that the number of events identified according to persistence ( $\geq 1$ day) is 193 (intense), 197 (weak), 215 (oceanic), and 242 (continental). Evidently, since factor 1 and factor 2 are orthogonal, it is possible to combine both factors such that one can identify SACZ cases typically intense (or weak) and oceanic (or continental) (Carvalho et al. 2002). However, in the present paper each category will be examined separately as follows.

To characterize patterns of enhancement/suppression and extent to the Atlantic Ocean of convective activity related to each SACZ category, we performed lag composites of OLR anomalies as shown in Figs. 3-6. Statistical significance is assessed by using a local $t$ test at the $95 \%$ level. The number of degrees of freedom was determined based on persistence of categories. Events were classified according to their persistence, considering as independent those that were separated from each other by 3 or more days. Lag composites in Fig. 3 indicate that an intense SACZ is preceded by the propagation of synoptic disturbances (cold fronts) from midlatitudes as seen at lags $-2,-1$ days (Fig. 3, topleft and right). At lag 0 , convection is enhanced from the Amazon toward the Atlantic Ocean (Fig. 3, middle). This remarkable and well-known DJF feature has been often observed by experienced forecasters and commonly referred to as the SACZ. At lags 1 and 2 days (Fig. 3, bottom left and right, respectively), one can observe the weakening of convective activity and northwest-southeast orientation, which indicates also the SACZ stationary characteristic.

Composites of weak category (Fig. 4, top left and right, respectively) indicate that large-scale suppression of convective activity over tropical South America does not seem to result from the propagation of transient disturbances or those are too weak to show a coherent pattern of negative anomalies, in contrast to the intense SACZ. The extent of positive OLR anomalies with maximum located over eastern Brazil at lags 0, 1, and 2 (Fig. 4, middle, left and right bottom, respectively) is also evident. Negative OLR anomalies are observed over southern Brazil and Uruguay from lags 0 to 2 days.

Lag composites of oceanic SACZ (Fig. 5) indicate that this category is preceded by the propagation of midlatitude disturbances (lag -2 to lag -1 : Fig. 5, top left and right). Note also the suppression of convective activity equatorward of the maximum convective activity at all lags. At lag 0 (Fig. 5, middle), the presence of a seesaw of suppressed and enhanced convection over the SACZ and subtropics, as discussed in Nogués-Paegle and Mo (1997), is clearly indicated. The oceanic characteristic of the SACZ and the seesaw remains at lag 1 (Fig. 5, bottom left) and then weakens at lag 2 (Fig. 5, bottom right) as convective activity moves southeastward over the Atlantic Ocean. Lag composites for the continental category (Fig. 6) shows that the region with suppressed convection observed equatorward of the propagating midlatitude disturbance at lags -2 and -1 (Fig. 6, top left and right) is now displaced southward compared to the oceanic category. Suppression of convection increases over the Atlantic Ocean as convective activity enhances over the continent at lag 0 (Fig. 6, middle), a feature almost symmetric to the oceanic SACZ (cf. Fig. 6, middle, with Fig. 5, middle). Negative anomalies over the continent become more elongated to the ocean as convection decays (Fig. 6, bottom left and right).

Composites of daily rainfall (Fig. 7) over Brazil provide additional evidence that our methodology is quite powerful in distinguishing different categories of SACZ. Intense SACZ (Fig. 7, top left) clearly resembles the DJF daily rainfall climatology, with maximum precipitation extending from the Amazon toward southeastern Brazil with a northwest-southeast orientation (cf. Fig. 1, top). These characteristics are consistent with the respective maximum of negative OLR anomalies obtained at lag 0 (Fig. 3, middle). Consistent with OLR anomalies (Fig. 4, middle), the weak category (Fig. 7, top right) shows a decrease of daily precipitation over central, eastern, and southeastern Brazil compared to the climatology (Fig. 1, top). The oceanic category (Fig. 7 , bottom left) indicates the displacement of maximum rainfall toward southeastern Brazil, a feature that does not resemble the climatology (cf. Fig. 1, top). The continental category (Fig. 7, bottom right) shows the retreat of maximum precipitation toward the center of the Amazon. Note that the maximum of negative OLR anomalies for the continental category (Fig. 6, middle) is mostly located in a region with scarce number of stations and intermittent observations, which restricts an appropriate identification of daily rainfall patterns in this area. Nevertheless, the continental category also shows an elongated feature toward southeast Brazil at lags 0 to 2 (Fig. 6, middle and bottom left and right). This is an important point to note about the methodology described here, that is, our approach clearly distinguishes the geographical variability of the SACZ. The SACZ features shown here seem to support the numerical simulations 

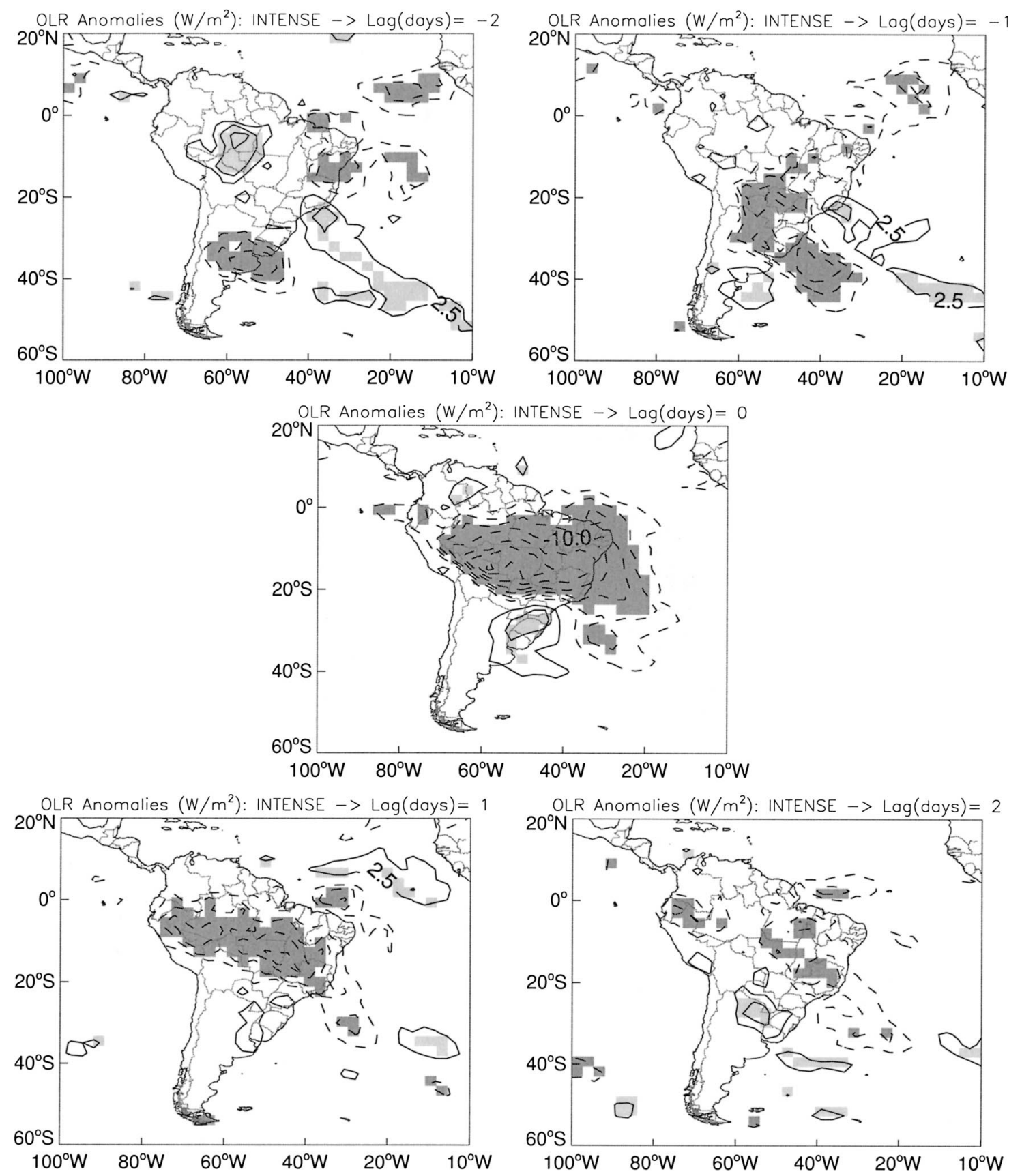

FIG. 3. Lag-composites of OLR anomalies for the intense SACZ category. Shading indicates statistical significance at 95\% confidence level. Dark (light) shading indicates negative (positive) OLR anomalies. Lags are indicated on the top of each frame. Horizontal resolution: $2.5^{\circ} \times 2.5^{\circ}$.

discussed in Barreiro et al. (2002), which suggest that the processes governing the variability of the oceanic and continental parts of the SACZ may be different. The authors argue that precipitation variability over land in tropical South America is dominated by internal variability of the atmosphere, whereas over the ocean it is more influenced by SST.

\section{SACZ categories and intraseasonal variations}

In this section, we investigate the linkages between SACZ occurrences and intraseasonal variations. This is accomplished by examining composites of OLR, lowlevel $(850 \mathrm{hPa})$ winds and $200-\mathrm{hPa}$ geopotential height anomalies (10-90 days). The composites were per- 

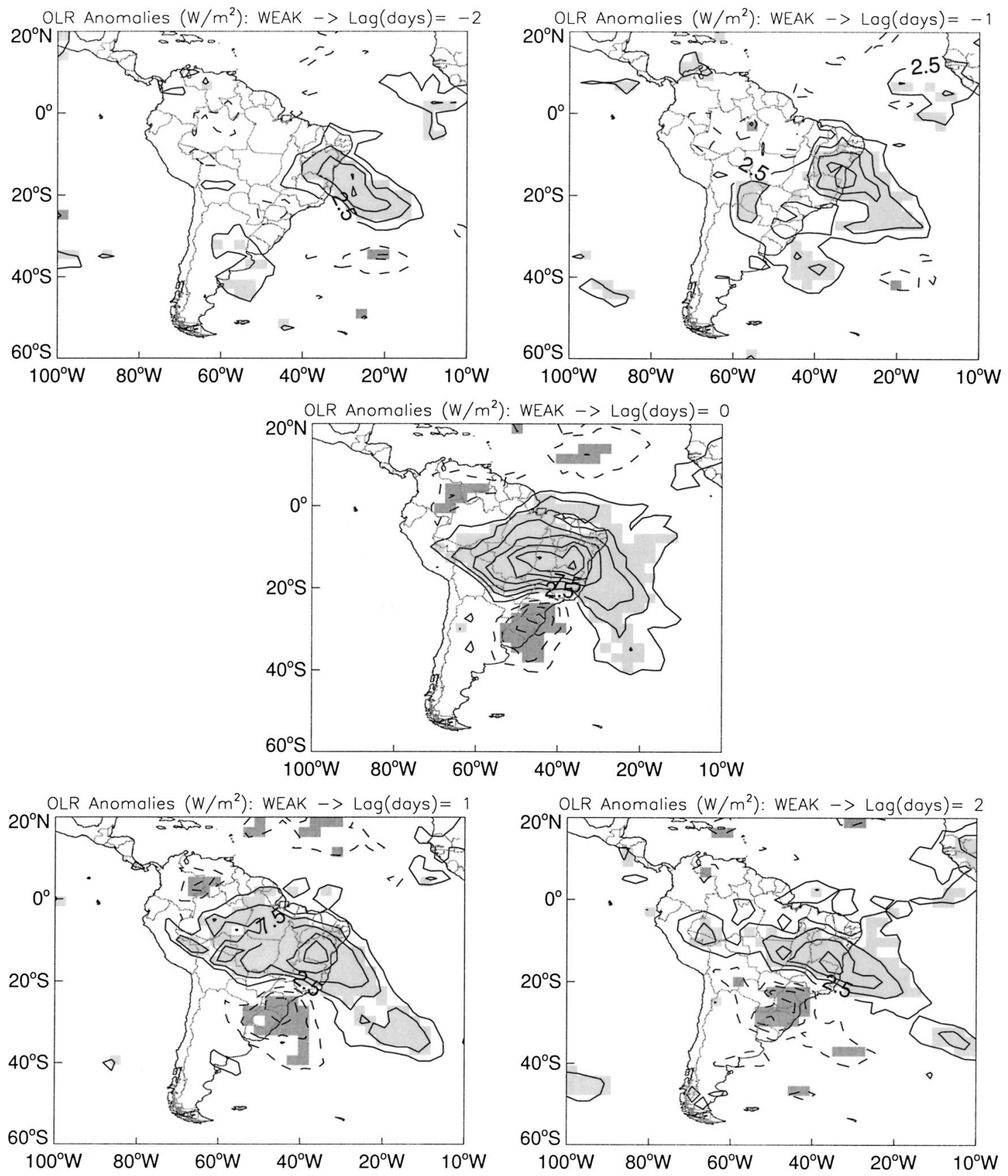

FIG. 4. As in Fig. 3 but for the weak category.

formed by averaging the intraseasonal anomalies on the dates of the SACZ categories discussed in the previous section. Likewise, statistical significance is assessed by using a local $t$ test at the $95 \%$ level. The main characteristics are summarized as follows.

\section{a. Intense SACZ category}

Intense SACZ category (Fig. 8, top) is related to coherent negative OLR anomalies extending over a large portion of tropical South America (Amazon basin to the Atlantic Ocean) with minimum values over eastern Brazil. Interestingly enough, the maximum in the intraseasonal negative anomaly is displaced toward northeast Brazil, comparatively to what is observed for the anomalies from the climatology (cf. Fig. 3 middle with Fig. 8 top) and is collocated with the maximum in the OLR standard deviation (Fig. 1, bottom). As discussed in detail in section 7 , the maximum in intraseasonal negative anomaly over northeast Brazil is likely linked to the 

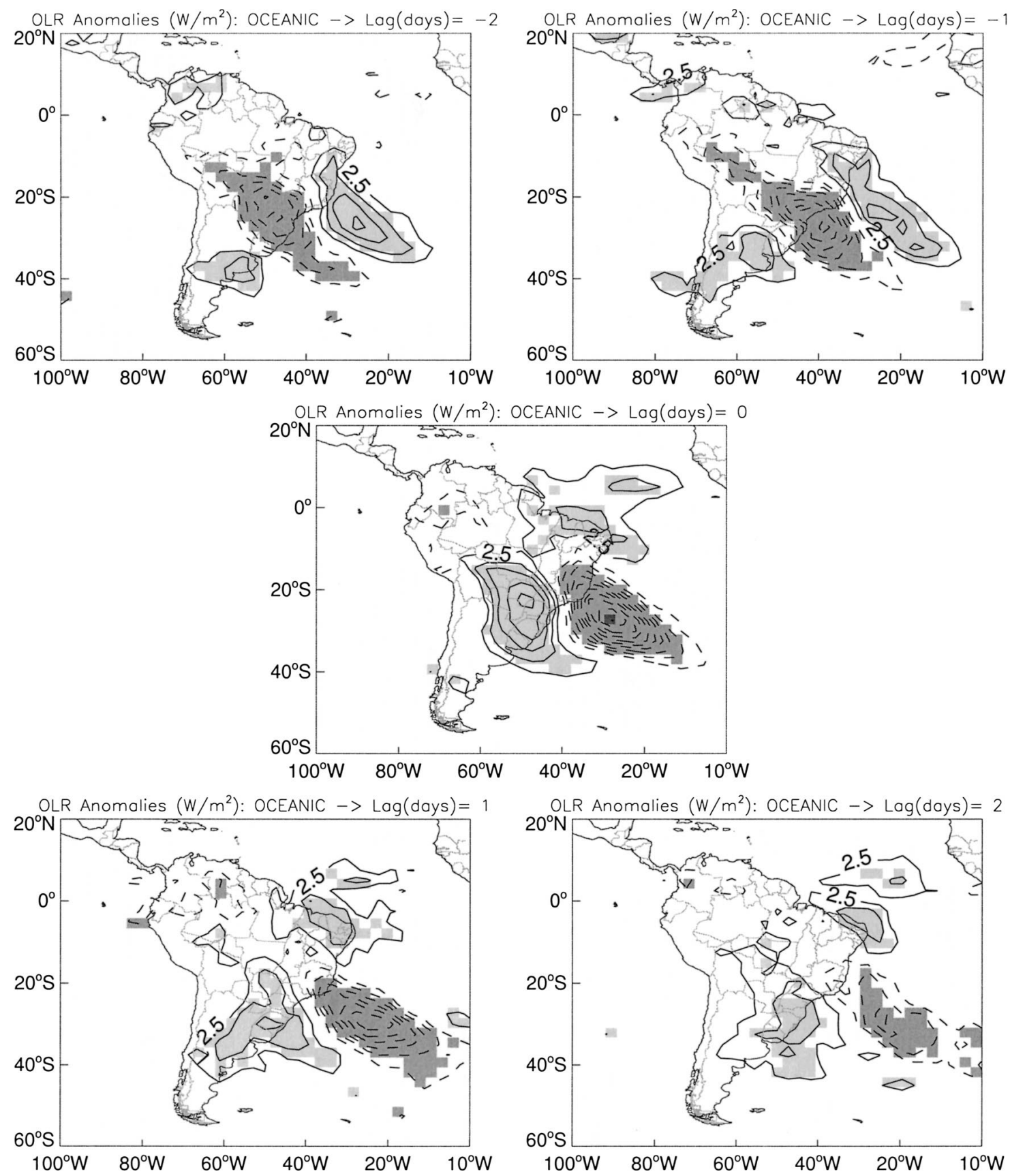

FIG. 5. As in Fig. 3 but for the oceanic category.

propagation of tropical anomalies in the Pacific Ocean (Jones et al. 1998; Jones 2000). The intense SACZ, when considered regardless of its convective activity over the Atlantic Ocean, does not show any indication of an intraseasonal "seesaw" pattern in tropical/subtropical convective activity similar to the one discussed by Nogués-Paegle and Mo (1997) and Liebmann et al. (1999). Jones and Carvalho (2002) demonstrated that intraseasonal variations in low-level wind regimes over Rondônia (approximately $10^{\circ} \mathrm{S}, 65^{\circ} \mathrm{W}$ ) modulate the
South American monsoon system, such that westerly (easterly) wind anomalies correspond to active (break) phases. This composite supports the idea that intense SACZ occurrences are related to westerly wind regimes (Rickenbach et al. 2002) and intraseasonal variations in SAMS (Jones and Carvalho 2002).

Geopotential height (200 hPa) anomalies (Fig. 9, top) do not show a coherent signal that might indicate the existence of a dipole of suppression/enhancement of tropical and subtropical convective activity or a mid- 

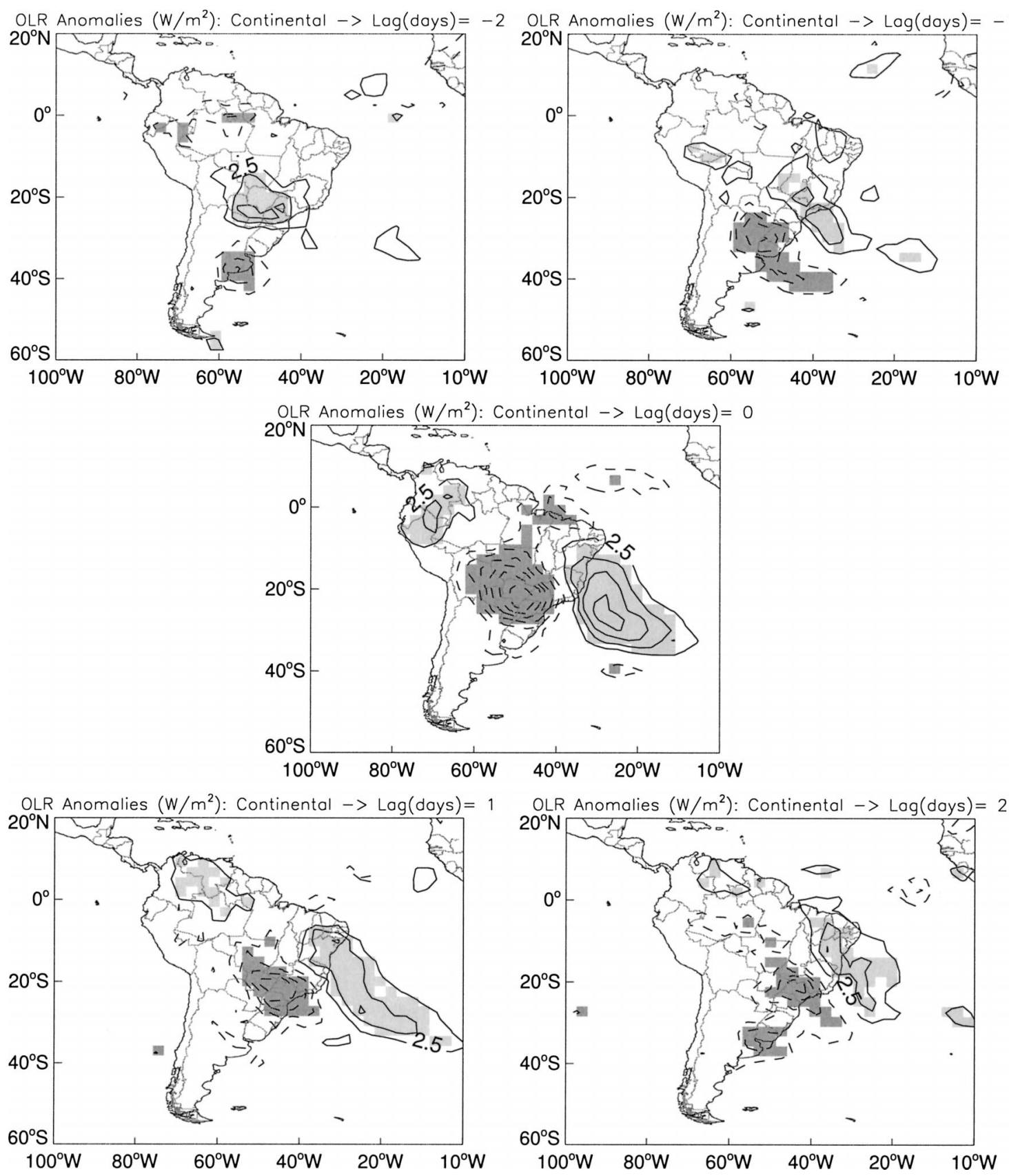

FIG. 6. As in Fig. 3 but for the continental category.

latitude wave train pattern modulating intense SACZ occurrences. Similar patterns of high-level winds (200 $\mathrm{hPa})$ and geopotential height $(200 \mathrm{hPa})$ were obtained in Carvalho et al. (2002) when extreme precipitation in São Paulo is observed during an intense and continental SACZ.

\section{b. Weak SACZ category}

Intraseasonal OLR anomalies during weak SACZ category (Fig. 8, second panel) indicate suppression of convective activity in a large area over tropical South America extending toward the Atlantic Ocean (opposite pattern to the intense SACZ). The maximum positive intraseasonal OLR anomalies are also observed over eastern Brazil. Low-level easterly wind intraseasonal anomalies over tropical South America are consistent with breaks in the monsoon regime (Jones and Carvalho 2002) and have been observed in association with suppression of convection in the SACZ (Rickenbach et al. 2002). Northerly intraseasonal anomalous winds are observed just east of the Andes with maxima over northern 

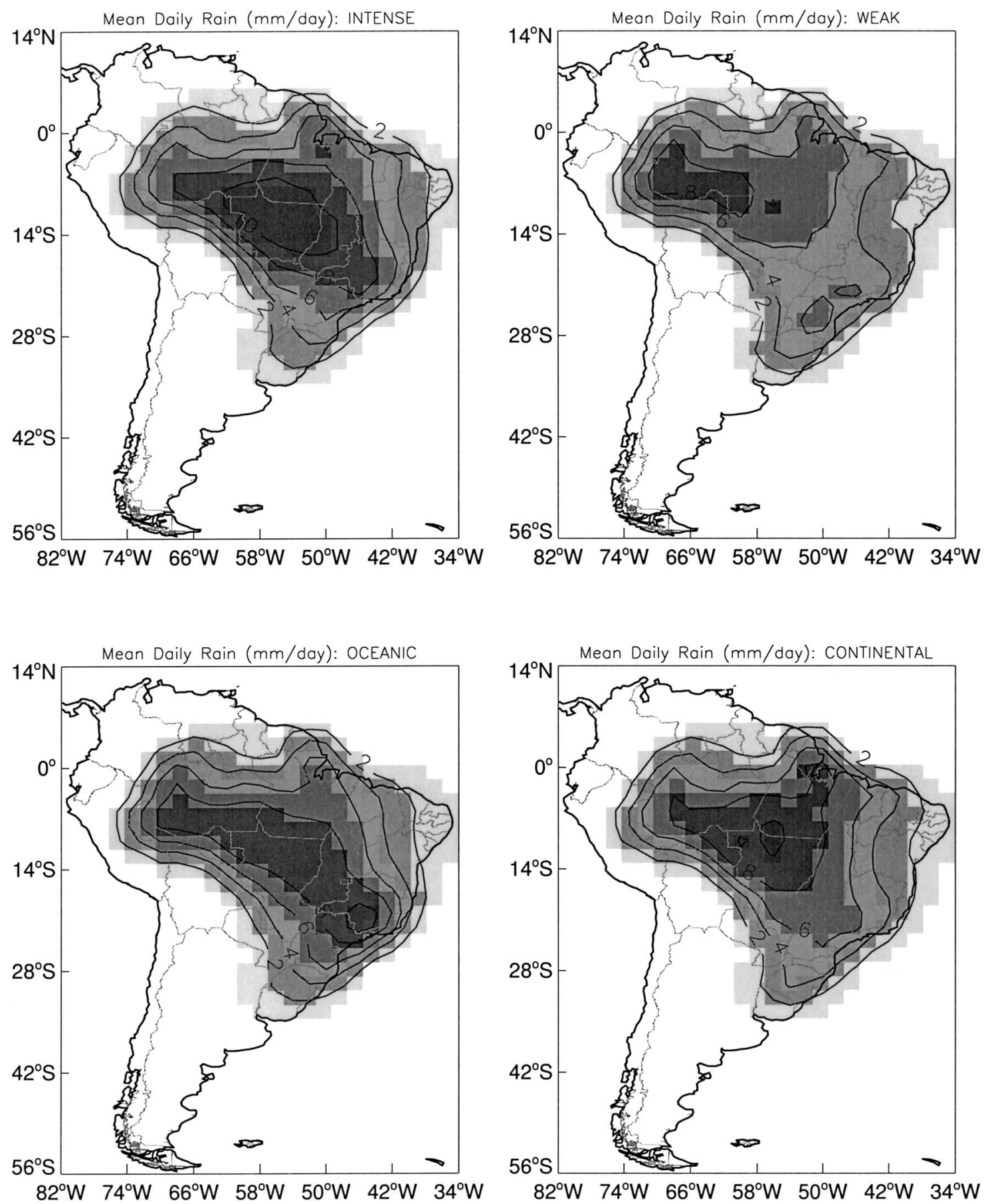

FIG. 7. Mean daily rainfall $\left(\mathrm{mm} \mathrm{day}^{-1}\right)$ in each category (indicated on the top of each frame).

Paraguay, a feature that has been previously noticed during a weak SACZ (Marengo and Soares 2002; NietoFerreira et al. 2003). Furthermore, the pattern of positive/negative OLR anomalies over subtropical southeastern South America resembles the dipole of convective activity discussed in Nogués-Paegle and Mo (1997) and Kiladis and Weickmann $(1992,1997)$. Geopotential height anomalies (Fig. 9, second panel) indicate a dipole of anomalies approximately with a north-south orientation over the western Atlantic Ocean, with negative magnitudes in midlatitudes $\left(\sim 45^{\circ} \mathrm{S}\right)$ and positive over the subtropics $\left(\sim 30^{\circ} \mathrm{S}\right)$. 


\section{c. Oceanic SACZ category}

Composites of OLR intraseasonal anomalies for oceanic SACZ occurrences (Fig. 8, third panel) indicate the existence of a tropical-subtropical dipole in convective activity as noted by Nogués-Paegle and Mo (1997) and Liebmann et al. (1999). The pattern of 200-hPa geopotential height anomalies (Fig. 9, third panel) is consistent with this result, which suggests that midlatitude Rossby wave propagation modulates the activity of the oceanic SACZ (Ambrizzi and Hoskins 1997; Kiladis and Weickmann 1997; Liebmann et al. 1999). An additional process that may play a role in the oceanic SACZ variability is a surface boundary condition (i.e., SST) as suggested in Barreiro et al. (2002).

\section{d. Continental SACZ category}

Composites of intraseasonal OLR anomalies indicate that the occurrence of SACZ activity organized over the continent is associated with suppression of convection off the northeast coast of Brazil (Fig. 8, bottom). Intraseasonal anomalies of 200-hPa geopotential height (Fig. 9 , bottom) also suggest a midlatitude wave train pattern modulating this category, but with opposite signs in the oceanic SACZ case.

To summarize, a few important points are worth mentioning. Typically, previous studies investigated the variability of the SACZ region using empirical orthogonal function techniques (Nogués-Paegle and Mo 1997; Nogués-Paegle et al. 2000). These techniques essentially maximize the total OLR covariance, which is large over southeast Brazil and the subtropical western Atlantic Ocean. Although much insight has being gained, those techniques fail to provide further information about SACZ variability. The factor analysis used here maximizes the total covariance of $\mathrm{OLR}_{200}$ properties, which incorporates the spatial variability (eccentricity and extent to the ocean) and intensity of the SACZ. Because factor 1 (related to intensity) and factor 2 (related to form) are orthogonal, the extent of the SACZ (continental vs oceanic) can be analyzed independently of its intensity. The results above indicate that the seesaw pattern of enhanced/suppressed convection in eastern tropical/subtropical South America and the midlatitude wave train activity identified in previous studies (Nogués-Paegle and Mo 1997; Liebmann et al. 1999) are actually related to convective activity displaced toward the Atlantic Ocean relative to the climatological mean position. The seesaw signal is also observed during weak SACZ events.

\section{SACZ persistence}

An important issue related to the SACZ is its persistence. For each category, persistence is defined here as the number of consecutive days of a given SACZ category, that is, a sequence of days observed below
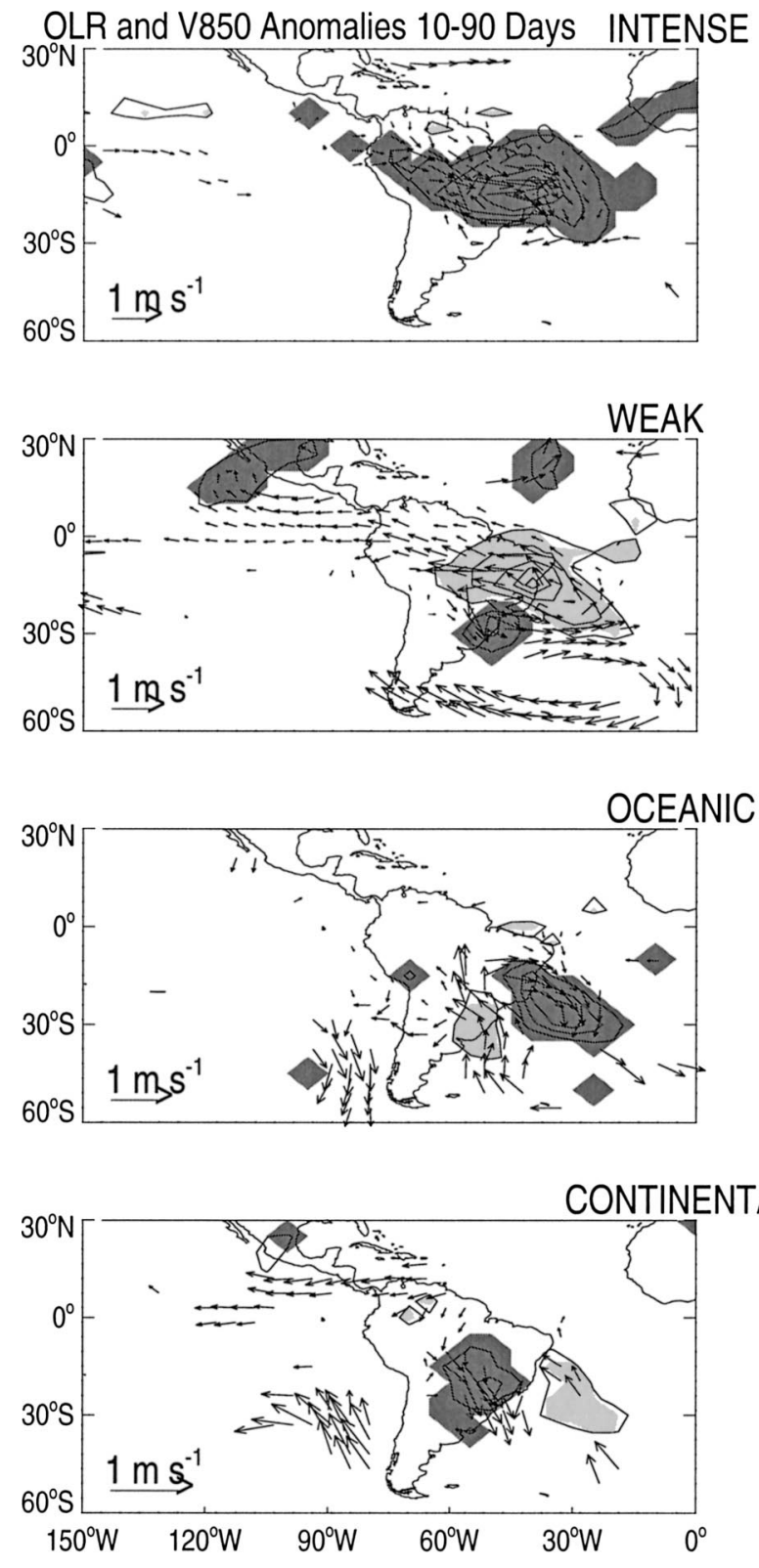

FIG. 8. Composites of OLR and 850-hPa wind anomalies (10-90 days) for each SACZ category (intense, weak, oceanic, and continental). Shading indicates statistical significance at the $95 \%$ confidence level. Dark (light) shading indicates negative (positive) OLR anomalies. Only wind anomalies that are statistically significant are displayed. Horizontal resolution: $5^{\circ} \times 5^{\circ}$.

(above) the 25th (75th) factor 1 and factor 2 percentiles. Figure 10 shows the frequency distribution of SACZ categories separated according to persistence as well as subseasonal variability (the number of independent events are also indicated). The total number of weak SACZ (persistence $\geq 2$ days) is approximately $10 \%$ larger than intense SACZ episodes with similar frequency distributions (Fig. 10, top left). The total number of oceanic and continental categories is nearly the same, 

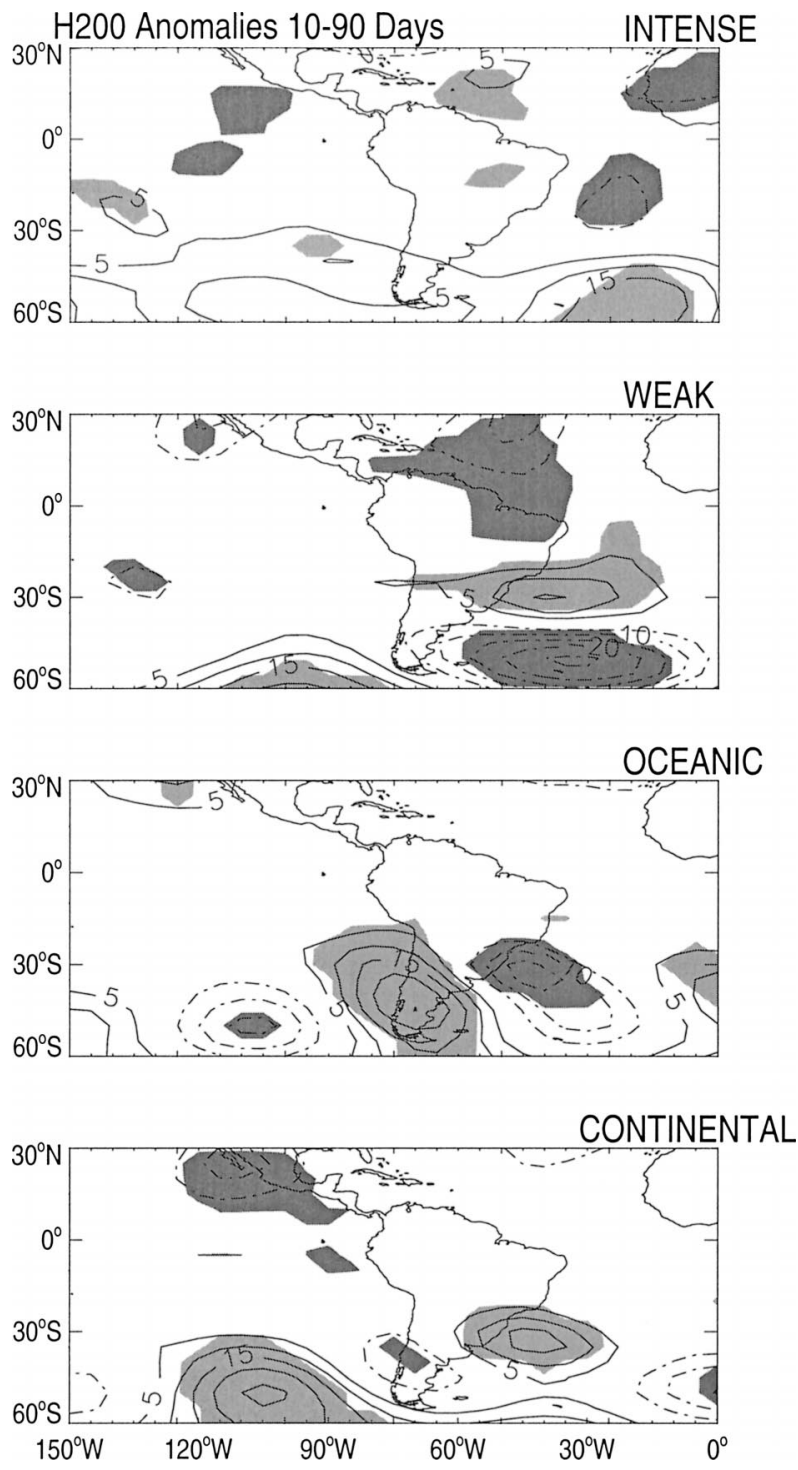

FIG. 9. As in Fig. 8 but for 200-hPa geopotential height anomalies.

and the distributions differ only by $13 \%$ and $10 \%$ for persistence equal to 2 and 3 days respectively (Fig. 10, top right). About $70 \%$ of both intense and weak (79\% for oceanic and continental) SACZ episodes occurred with persistence $\leq 4$ days. The subseasonal frequencies of categories seem to depend on persistence (Fig. 10, bottom left and right). For persistence $\leq 3$ days, there is no statistically significant variation in the frequency of intense, weak (Fig. 10, bottom left) and continental events (Fig. 10, bottom right). However, for persistence $\geq 4$ days, the frequency of intense events decreases from December to February (Fig. 10, bottom left), as well as the frequency of the oceanic SACZ (Fig. 10, bottom right). The continental category with persistence $\geq 4$ days (Fig. 10, bottom right) is more frequent in January than December and February. Weak events are well distributed during DJF for all persistence.
The time interval $(\Delta T)$ between SACZ occurrences that persisted longer than 3 days in a given category is displayed in Fig. 11. Although the median (6 days) and interquartile ranges are similar for weak and intense SACZ categories, $\Delta T$ for intense episodes have the highest variability compared to other categories. Consequently, the intense SACZ category has the largest skewness coefficient in the $\Delta T$ distribution, which is implied in the largest total $\Delta T$ observations longer than 20 days. The $\Delta T$ distributions for oceanic/continental categories are similar, with equal median and interquartile range. Nonetheless, the $\Delta T$ distribution of the continental SACZ category is less skewed than the respective oceanic distribution.

\section{Interannual variations of $\mathrm{SACZ}$ categories}

Figure 12a shows that SACZ categories that persist longer than 2 days occur every year but not with the same frequency. To understand the role of El Niño/La Niña episodes in modulating the interannual variability of SACZ categories, we computed the number of events observed in distinct ENSO phases. We selected 6 years in each phase to ensure that an equal number of years is analyzed; years used in this analysis are indicated on top of each frame of Figs. 12b-d. Warm and cold ENSO phases are based on SST anomalies in the Niño-3.4 region and are identified by the NCEP/Climate Prediction Center. Categories are also separated according to persistence. Using these criteria, it is observed that intense and weak categories have the same relative frequency during the three phases of ENSO independent of persistence (not shown). However, the frequency of oceanic and continental events seems to be modulated by ENSO phases, which is more evident for long persistence. Warm (cold and neutral) ENSO phases seem to favor the occurrence of oceanic (continental) categories (Figs. 12b-d). For oceanic events with persistence longer than 3 days (35 events), about $50 \%$ occurred during warm phases (Fig. 12b), whereas about $25 \%$ occurred during neutral and cold phases (Figs. $12 \mathrm{c}, \mathrm{d})$. The same trend is also observed if one considers only events with persistence $\geq 5$ days (Figs. 12b-d). An opposite trend is observed for continental category with persistence $>3$ days ( 24 events). That is, about $46 \%$ of continental events with persistence $\geq 4$ days occurred during neutral and cold phases (Figs. 12c,d), whereas only $8 \%$ (2 events) occurred during warm phases (Fig. $12 b)$.

Nogués-Paegle and Mo (1997) and Hoerling and Kumar (2000) showed that an enhancement of precipitation in southeast Brazil extending toward the subtropical Atlantic (what has been subjectively defined as SACZ) is likely modulated by ENSO. The strengthening of the subtropical jet toward the western South Atlantic has been observed for extreme precipitation that occurred during ENSO episodes over São Paulo (southeastern Brazil) (Carvalho et al. 2002), possibly as a consequence 

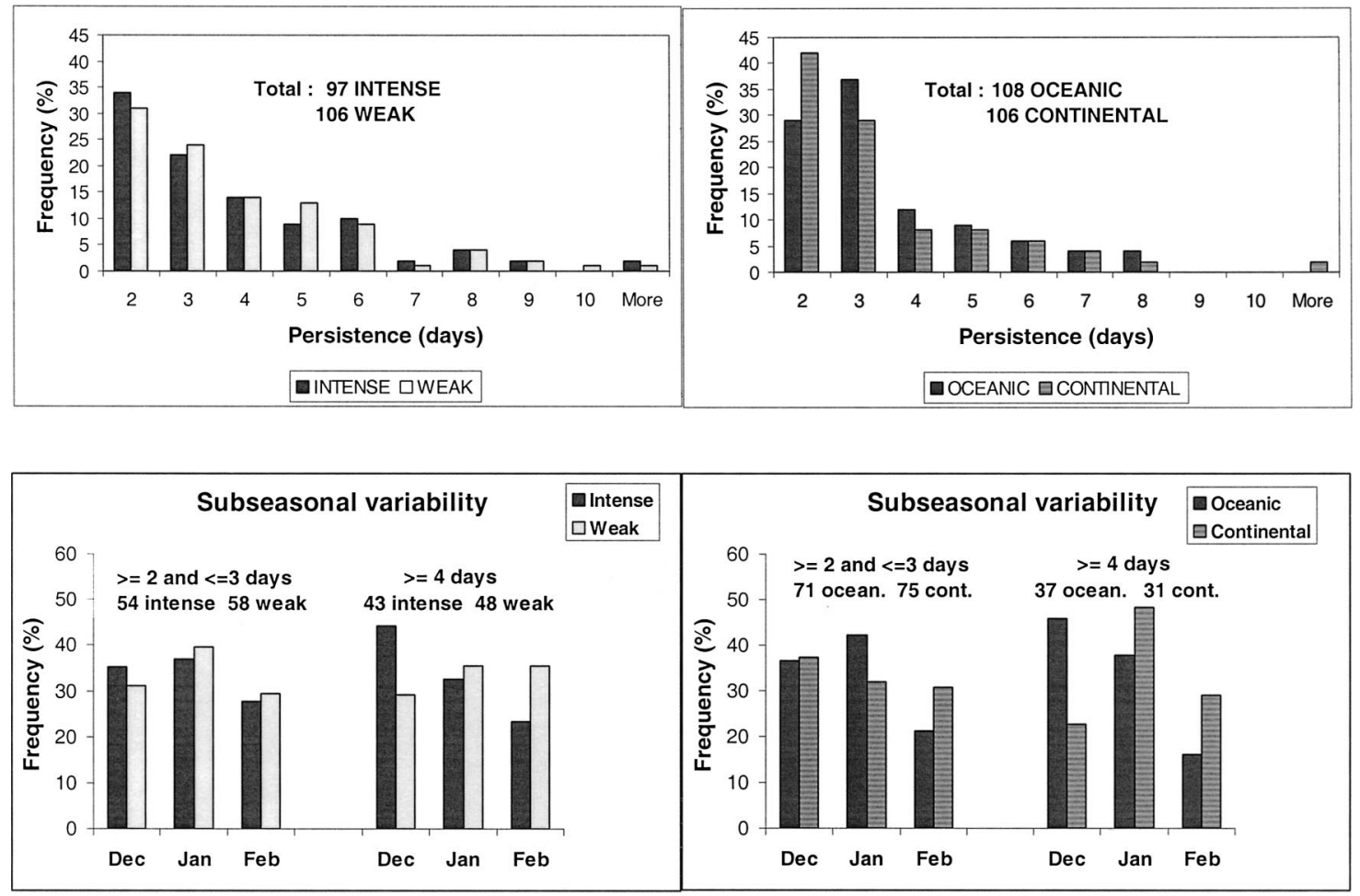

FIG. 10. Frequency distribution of SACZ categories as function of persistence (days): intense and weak (top left); oceanic and continental (top right). Subseasonal variability of categories separated according to persistence: intense and weak (bottom left) and oceanic and continental (bottom right).

of the migration of the equatorial Indo-Pacific convection (Grimm and Silva Dias 1995). Although these perturbations are stronger from austral winter to spring (Kousky and Ropelewski 1989), a similar rationale could be applied to explain the extension of convective activity in the SACZ toward the Atlantic Ocean. This configuration of the subtropical jet could favor the SACZ stationarity and also the occurrence of anomalous

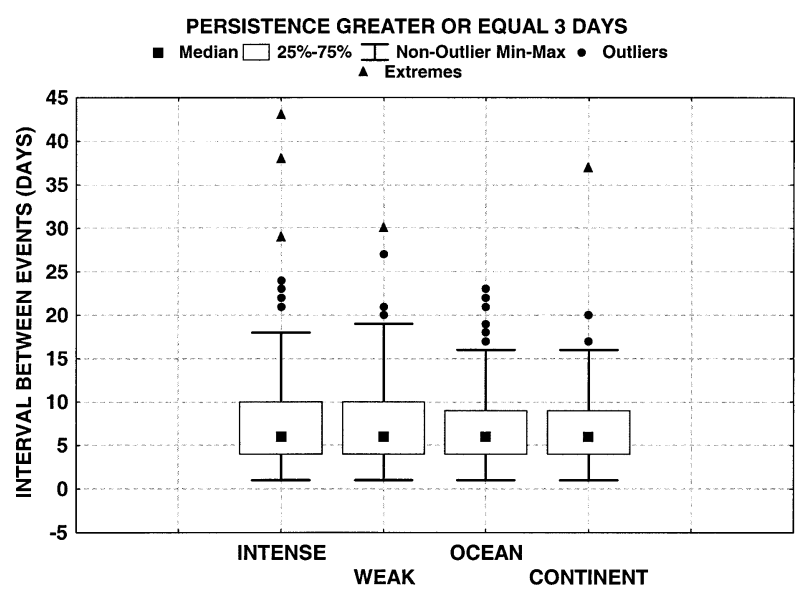

FIG. 11. Box-plot diagram of statistical properties of the time interval between events in the same SACZ category. Outliers are data point values $\geq 1.5$ times the interquartile range. Extremes are data point values $\geq 3.0$ times the interquartile range. precipitation over southeastern South America (Carvalho et al. 2002; Liebmann et al 2001; Grimm and Silva Dias 1995), which is consistent with results shown in Fig. 7 (bottom left). Nonetheless, the mechanism that inhibits the occurrence of the stationary continental category during warm episodes is not totally clear yet.

\section{Tropical intraseasonal activity and the SACZ}

\section{a. The MJO and tropical intraseasonal anomalies}

The relationships between the MJO and SACZ activity are now investigated. We first examine the MJO life cycle by performing an EOF analysis of 10-90 days bandpass OLR anomalies (DJF 1979-2000). Several previous studies have shown that the first two eigenvectors are separated from the remaining ones and together they describe the propagating behavior of the oscillation (Hendon and Salby 1994; Maloney and Hartmann 1998; Jones et al. 1998; Jones 2000). To identify patterns of convection in different phases of an active propagating MJO, we performed composites for cases when the amplitudes of the two leading principal components were above one (or below minus one) standard deviation (Fig. 13). These phases are indicated by $\mathrm{PC} 1+, \mathrm{PC} 1-, \mathrm{PC} 2+$, and $\mathrm{PC} 2-$. The results show the typical eastward-propagating behavior of the $\mathrm{MJO}$, in which enhanced convection originates in eastern Africa, 
intensifies over the Indian Ocean, and propagates into the western Pacific (Hendon and Salby 1994; Maloney and Hartmann 1998; Jones 2000). A relevant feature for the discussion of the present study is the PC2- phase, whereby suppressed convection is observed over the maritime continent and enhanced convective activity is located over eastern South America. As demonstrated next, this MJO phase modulates persistence of the SACZ and occurrence of extreme rainfall in Brazil.

\section{b. The MJO activity and persistence of the SACZ}

The possible role of the MJO in modulating persistence of weak and intense SACZ was investigated in the following way. First, we separated the SACZ categories (intense/weak and continental/oceanic) into cumulative intervals of persistence (i.e., number of events persisting longer than 2, 3, 4, and 5 days). This frequency distribution was additionally separated according to the phase of the MJO. Events that did not occur during any of the MJO phases were included in "OTHERS." The results are displayed in Fig. 14. As an example, about $33 \%$ of intense SACZ events (Fig. 14, top left) that persist more than 2 days also occur during the $\mathrm{PC} 2$ - phase of the MJO. More specifically, the results show that as the persistence of intense SACZ episodes increases, the frequency of events associated with PC2also increases. For intense SACZ with persistence $\geq 3$ days, the frequency of episodes associated with PC2is already larger than any other situation considered here. About $50 \%$ of intense SACZ with persistence $\geq 4$ days are observed in $\mathrm{PC} 2-$, whereas this frequency increases to about $56 \%$ for persistence $\geq 5$ days. For the weak category (Fig. 14, top right), PC2+ plays an almost equivalent role as "OTHERS" except for persistence $\geq 5$ days. Likewise, almost the same distribution in $\mathrm{PC} 1+, \mathrm{PC} 1-, \mathrm{PC} 2+, \mathrm{PC} 2-$ and OTHERS are observed for continental (Fig. 14, bottom right) aspects, whereas OTHERS are more frequent for persistent oceanic SACZ. The exception is observed for persistence $\geq 5$ days, in which $\mathrm{PC} 1+$ is more frequent (Fig. 14, bottom left). This analysis indicates that the MJO phase characterized by PC-2 plays an important role in modulating persistence of intense SACZ episodes. We recall that the distribution of the time interval between intense and persistent episodes (persistence $\geq 3$ days) is skewed toward larger values (Fig. 11), which is consistent with the hypothesis that tropical intraseasonal activity may modulate long persistence of an intense SACZ.

\section{Extreme precipitation over Brazil}

\section{a. Relationships with SACZ categories}

Carvalho et al. (2002) showed that the occurrence of summertime extreme precipitation events in southeastern Brazil (i.e., São Paulo state) is closely related to SACZ activity. In that study, extreme precipitation was

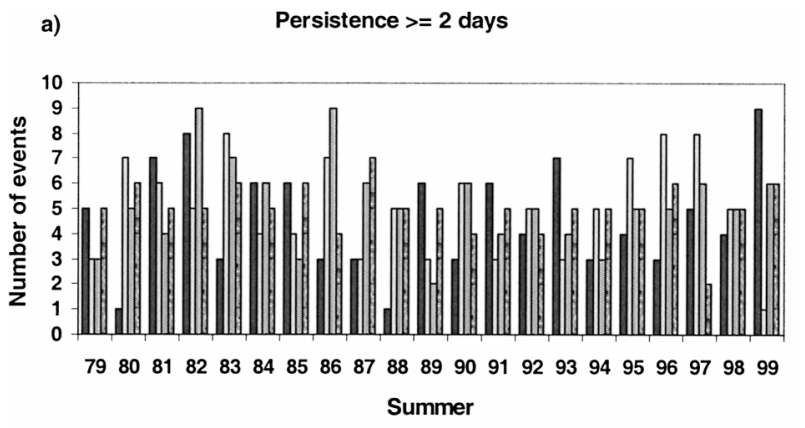

$\square$ INTENSE $\square$ WEAK $\square$ OCEANIC $\square$ CONTINENTAL

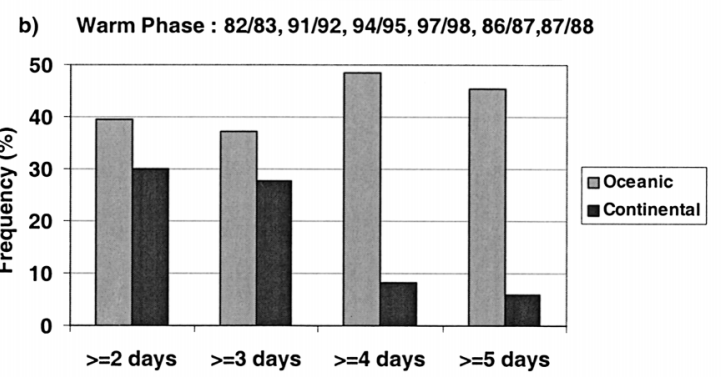

c) Neutral Phase : 80/81, 81/82, 85/86, 89/90, 93/94*, $96 / 97$

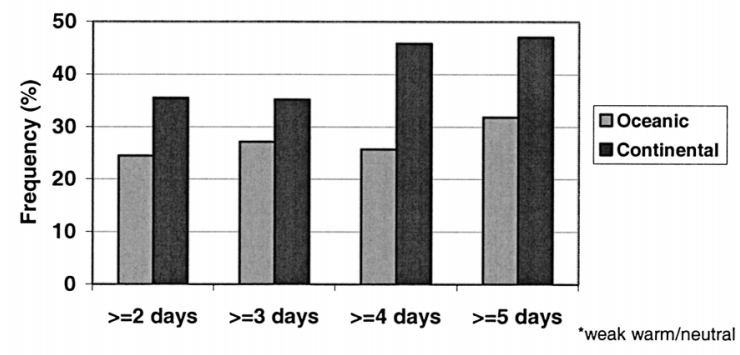

d) Cold Phase : 83/84, 84/85, 88/89, 95/96, 98/99, 99/00

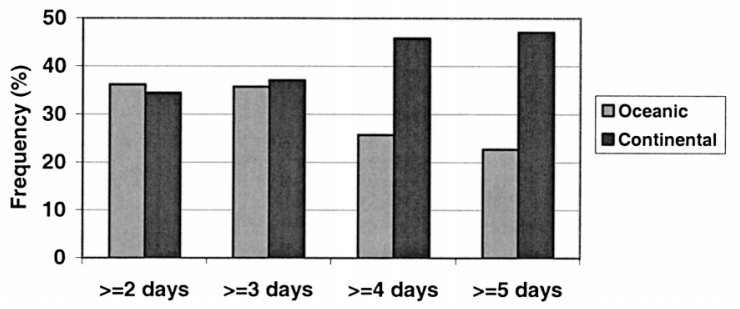

FIG. 12. (a) Annual variability of SACZ categories with persistence $\geq 2$ days; (b) relative frequency of oceanic and continental SACZ that were observed over 6 yr during an ENSO warm phase; (c) relative frequency of oceanic and continental SACZ that were observed over 6 yr during an ENSO neutral phase; (d) relative frequency of oceanic and continental SACZ that occurred during an ENSO cold phase. Years analyzed in each ENSO phase are indicated on the top of each frame. All frequencies are relative to $18 \mathrm{yr}$ of observation. Categories are also separated according to classes of persistence.

defined when daily precipitation in a given station was above $16 \%$ of its average seasonal total precipitation. About $65 \%$ of the cases occur during an intense SACZ and nearly $35 \%$ during weak cases. In the same study, the authors demonstrated that the spatial variability of extreme precipitation depends on both intensity and 

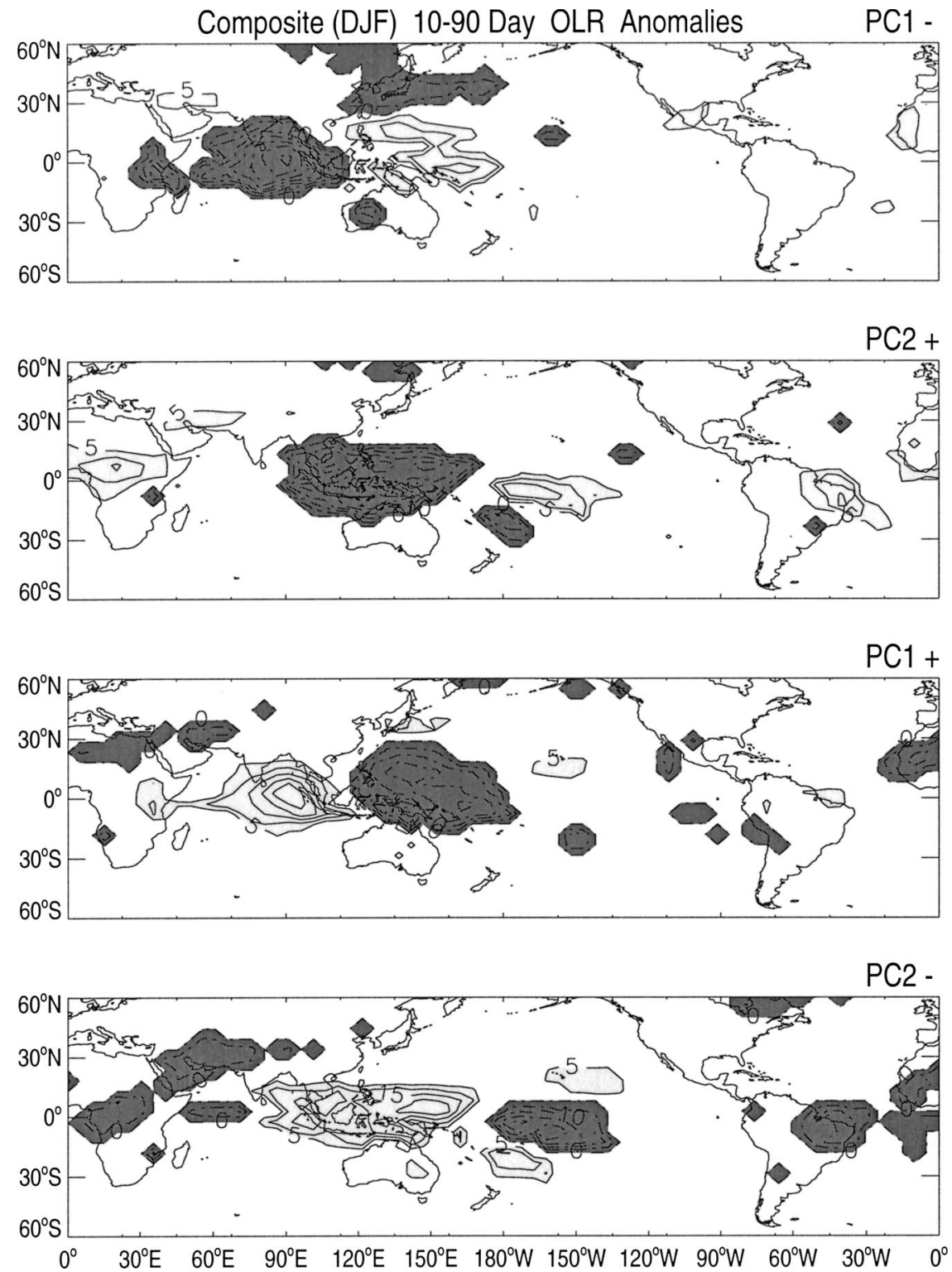

FIG. 13. Composites of 10-90-day OLR anomalies based on the magnitudes of the first two leading principal components (PC1 and PC2).

form (oceanic or continental aspects) of the SACZ. They have also suggested that distinct dynamical mechanisms might modulate the intensity and form of the SACZ and, consequently, the regional aspects of the extreme precipitation.

In this study, we extend our previous analysis to investigate the importance of the SACZ in modulating the spatial characteristics of extreme precipitation over Brazil. Extreme precipitation events are defined as those in which the daily total is above the 95th percentile. We performed this computation taking precipitation time series at each grid point. The DJF 95th percentile $(\mathrm{mm}$ day $^{-1}$ ) is displayed in Fig. 15. The 95th percentile follows approximately the spatial characteristics of the mean precipitation with maximum over central Amazon decreasing toward northeast Brazil.

To further understand the SACZ contribution to the occurrence of extreme precipitation, we computed the 95th percentile of a sample of 438 days obtained in each SACZ category, regardless of persistence. Differences between the 95th daily rainfall percentiles obtained for each category $\left(\mathrm{mm} \mathrm{day}^{-1}\right)$, for each grid point, and the corresponding DJF 95th percentile (or the DJF 95th climatology) are shown in Fig. 16. For intense SACZ, larger differences (more than $4 \mathrm{~mm} \mathrm{day}^{-1}$ ) are observed over central-southeastern Brazil (Fig. 16, top right), which means that the 95th percentile increased from about 25 to $30 \mathrm{~mm}$ day $^{-1}$ or more in that region (cf. 


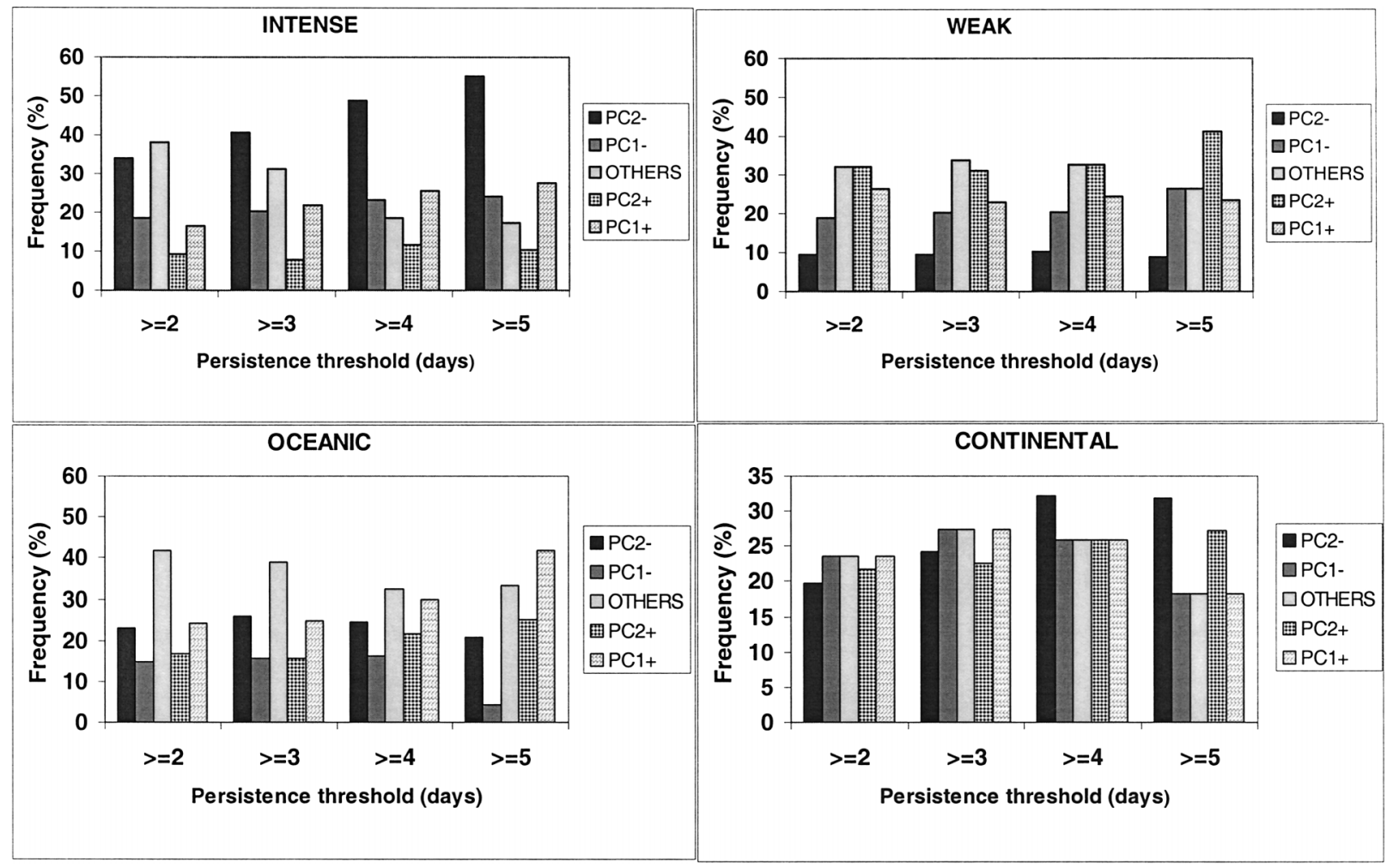

FIG. 14. Frequency distribution of SACZ characteristics as a function of persistence and phase of the MJO shown in Fig. 10 (PC1 \pm , PC2 \pm ). Events that did not happen in any MJO active phase are included in the OTHERS category. (top left) Intense, (top right) weak, (bottom left) oceanic, and (bottom right) continental category.

Fig. 15 with Fig. 16, top left). The enhancement of the 95th percentile in that region represents an increase in the climatological DJF 95th precipitation percentile of about $25 \%$. For an intense SACZ, the pattern of difference from climatology of the 95 th rainfall percentile $\left(\mathrm{mm}\right.$ day $\left.^{-1}\right)$ is equivalent to the pattern of increase in frequency of days that reached the DJF 95th rainfall percentile (not shown).

Opposite features are found for the weak category (Fig. 16, top right). The 95th rainfall percentile decreases as much as $7 \mathrm{~mm} \mathrm{day}^{-1}$ from the Amazon toward central-eastern Brazil in a region where the DJF 95th percentile is between 25 and $30 \mathrm{~mm}^{\text {day }}{ }^{-1}$. These observations are consistent with the mean daily rainfall features shown in Fig. 7. For the oceanic SACZ, there is an increase of the 95 th percentile over the states of southeastern Brazil, which is consistent with results shown in Carvalho et al. (2002). The decrease of the 95th percentile of precipitation over the central Amazon during this category is also a feature observed for the mean daily rainfall (cf. Fig. 16, bottom left, with Fig. 7 , bottom left). The negative differences of the 95th daily rain percentile and the DJF 95th daily rain percentile over southeastern Brazil for the continental category is opposite to the trend of the oceanic category. We recall that the region where the maximum in negative OLR anomalies are observed for the continental category (Fig. 6, middle) are mostly located over the Pantanal in Brazil, Paraguay, and parts of Bolivia-an area that does not have a good coverage of stations and has intermittent observations (where available)—which affects the reliability of the 95 th percentile.

\section{b. Relationships with MJO activity}

To examine the role of the MJO in modulating extreme precipitation over Brazil we computed the 95th percentile observed during the four phases of the leading $\mathrm{PCs}(\mathrm{PC} 1+, \mathrm{PC} 1-, \mathrm{PC} 2+, \mathrm{PC} 2-)$. The number of days in each phase was 300 for $\mathrm{PC} 1+, 277$ for $\mathrm{PC} 2+, 240$ for $\mathrm{PC} 1-$, and 248 for $\mathrm{PC} 2-$. Figure 17 shows the difference between the climatological DJF 95th percentile and the 95th rainfall percentile obtained for each MJO phase. The PC2 - phase (Fig. 17, top left) characterizes the largest spatial extent of the MJO influence. As discussed in section 7, this MJO phase seem to modulate persistence of an intense SACZ, which is consistent with the extent and location of the spatial pattern of positive differences (cf. Fig. 16, top left, with Fig. 17, top left). However, it is noticeable that the local maximum is over northeast Brazil, which has not been observed during an intense SACZ. This is not surprising though, given that this phase of the MJO characterized by intense convective activity over the central Pacific 
DJF 95th Daily Rainfall Percentile ( $\mathrm{mm} /$ day)

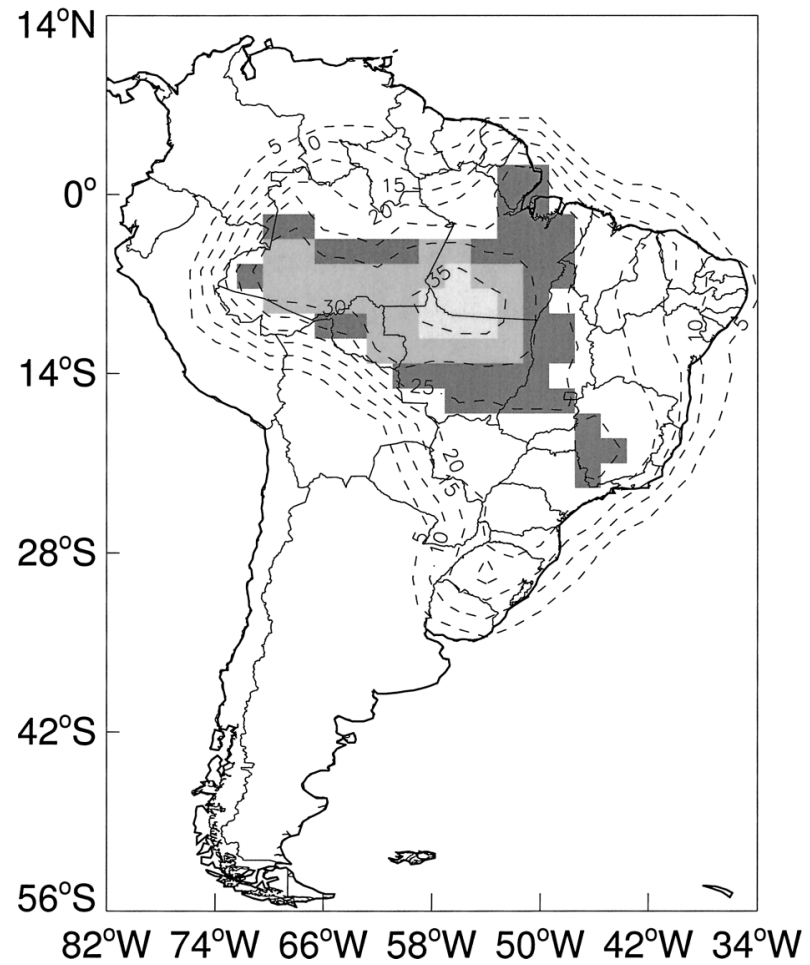

FIG. 15. Spatial distribution of the 95th percentile of daily gridded precipitation $\left(2^{\circ} \times 2^{\circ}\right.$ lat/lon horizontal resolution) over Brazil. Gridded precipitation with 95 th percentile above $25 \mathrm{~mm} \mathrm{day}^{-1}$ is highlighted.

and suppression over Indonesia is associated with negative OLR anomalies over eastern Brazil, which is located north of the climatological SACZ position (Fig. 13, bottom). This aspect emphasizes the key role of the MJO in modulating the precipitation regime over eastern tropical South America, which includes the semiarid region in Brazil known as the Nordeste. The increase in the 95th rainfall percentile of more than $5 \mathrm{~mm} \mathrm{day}^{-1}$ over the region where the DJF 95th percentile is between 15 and $20 \mathrm{~mm} \mathrm{day}^{-1}$ (Fig. 15), represents a shift in the climatological 95th percentile of about 25\%-30\%.

In contrast, the $\mathrm{PC} 2+$ phase (Fig. 17, bottom left) shows a region with negative differences with respect to the climatology over a large part of central-eastern Brazil, with similar form and magnitude as observed for weak SACZ. This is consistent with the positive OLR anomalies over eastern and northeastern Brazil observed during the phase of the MJO where intense convective activity is located over Indonesia, described by $\mathrm{PC} 2+$ (Fig. 13, second panel). Note also the increase of $4 \mathrm{~mm}$ day $^{-1}$ in the DJF 95th percentile over southern Brazil, which is twice as much as the $2 \mathrm{~mm}^{-1 a y^{-1}}$ shown for the weak SACZ category (cf. Fig. 16 top right with Fig. 17 bottom left). The PC1 - and PC1+ phases (Fig. 17 , top right and bottom right) do not show any strong signal of frequency of extremes over Brazil. This is not an entire surprise, since no coherent signal in convective activity is observed over South America during these phases of the MJO (Fig. 13, first and third panels).

Quantitatively, the excess or deficit of rain is larger for the 95th percentile compared to the median $(\mathrm{mm}$ day $^{-1}$ ) given the characteristics of the tail of the rainfall distribution. Differences (absolute value) less than $3 \mathrm{~mm}$ day $^{-1}$ are observed with a spatial pattern similar to the 95th percentile for the oceanic, weak SACZ and PC2phase of the MJO. Similarly, differences (absolute value) less than $2 \mathrm{~mm}$ day $^{-1}$ are observed for the intense SACZ, whereas the continental SACZ and all other MJO phases did not show differences larger than $1 \mathrm{~mm}^{\text {day }}{ }^{-1}$ (not shown). Nonetheless, a few millimeters in the daily median can sometimes signify a large fraction of the climatological median, especially in dry areas such as the northeast of Brazil.

\section{Conclusions}

This paper examined the variability of convective activity and large-scale circulation associated with the SACZ during the austral summer. Specifically, this study is composed of four main elements. First, an objective method to identify the SACZ and characterize its intensity, geographic position (continental vs oceanic), and persistence has been developed. Factor analysis was applied to identify typical patterns in SACZ convective activity such that four categories were determined: intense (factor 1, related to intensity, below its 25 th percentile); weak (factor 1 , above its 75 th percentile); oceanic (factor 2, related to form, below its 25th percentile); continental (factor 2, above its 75th percentile). Second, we examined each category with respect to the evolution of convective activity and rainfall, persistence, and interannual variations. Next, we investigate intraseasonal variations (10-90 days) in convection and large-scale circulation associated with different categories of SACZ episodes, addressing the importance of the MJO in modulating persistence of the SACZ. Since the SACZ and MJO have substantial influence on the variability of rainfall in Brazil, we investigated the relationships of these modes with the occurrence of extreme precipitation.

In agreement with previous studies, intraseasonal variations (10-90 days) in the SACZ are quite significant. The intense SACZ category is associated with OLR intraseasonal anomalies over a large area of tropical South America extending from the western Amazon to the Atlantic Ocean. The maximum in enhanced convection in the SACZ on intraseasonal time-scales is displaced eastward in relation to the maximum of anomalies from climatology. This observation is likely linked to the propagation of tropical intraseasonal anomalies in the equatorial Pacific. Intraseasonal low-level westerly wind anomalies over tropical South America are associated with the intense SACZ, which is consistent with active phases of the monsoon regime (Jones and Carvalho 

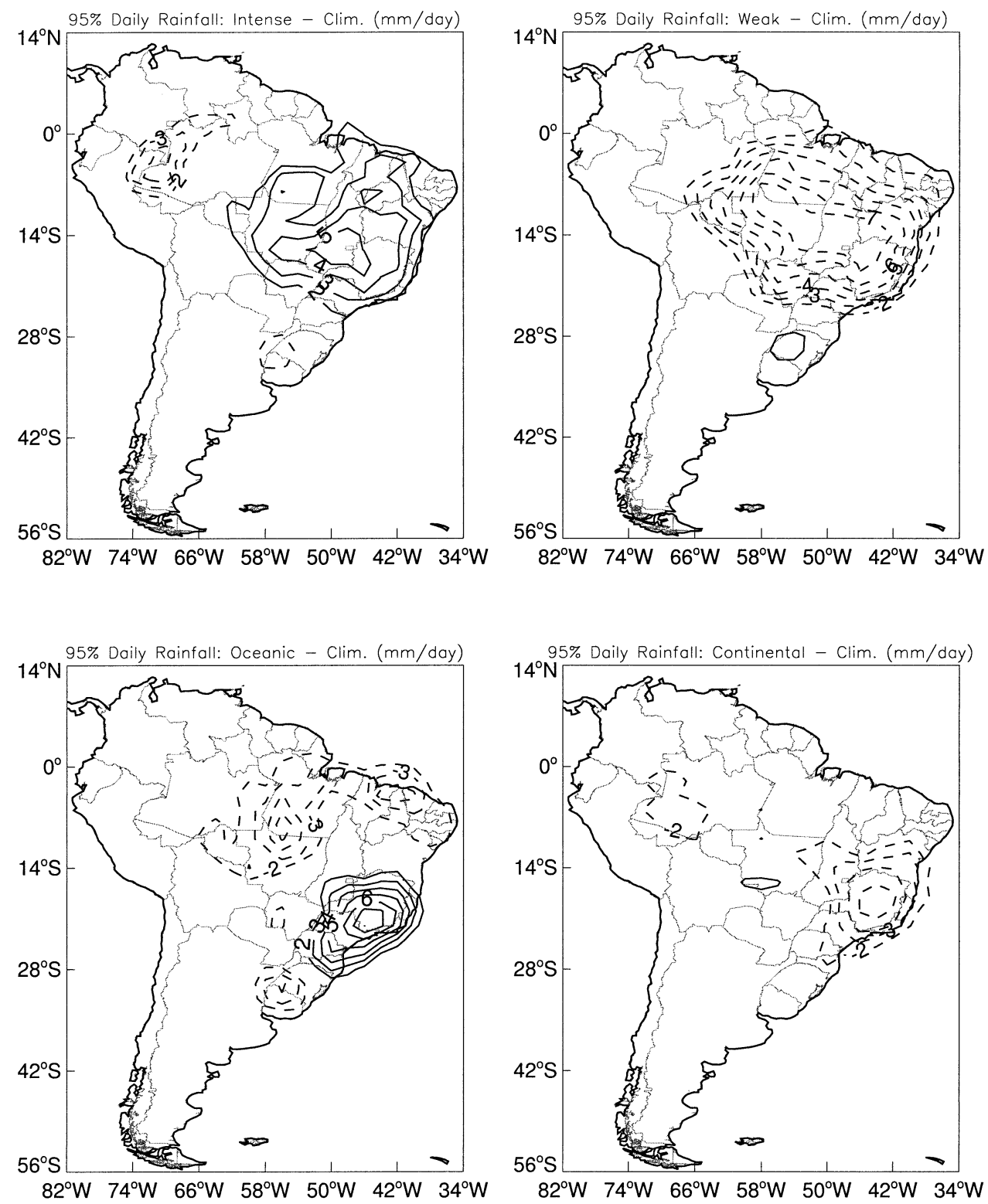

FIG. 16. Difference between the 95th percentile rainfall for SACZ categories and the climatological (Clim) DJF 95th percentile rainfall. Dashed lines indicate negative differences and solid lines positive differences.

2002). The "seesaw" pattern (Nogués-Paegle and Mo 1997) is well defined only when the SACZ is displaced toward the Atlantic Ocean. The weak SACZ category is observed with enhancement of convection over southern Brazil and Uruguay, which is also indicative of the seesaw feature. Intraseasonal low-level easterly wind anomalies over tropical South America are associated with the weak SACZ, which is also consistent with breaks in the monsoon regime discussed in Jones and Carvalho (2002). Oceanic and continental aspects of the SACZ are clearly related to the midlatitude wave train pattern identified in previous works (Liebmann et al. 1999). Therefore, to some extent, there is no contradiction between our methodology and the Liebmann et al. (1999) or Nogués-Paegle and Mo (1997) approaches to identify the SACZ since the oceanic aspect, which seems to be associated with the propagation of midlatitudes wave trains, explains part of the total covariance of the SACZ.

Although SACZ categories persisting more than 3 days are observed in every summer season, ENSO phases seem to modulate the number of oceanic and continental persistent events with no clear influence on intense or weak categories. By considering 6 years in each ENSO phase, the number of persistent (persistence $\geq$ 4 days) oceanic SACZ was twice as large as the number of events observed during neutral and cold phases. An opposite relationship is observed for the continental 

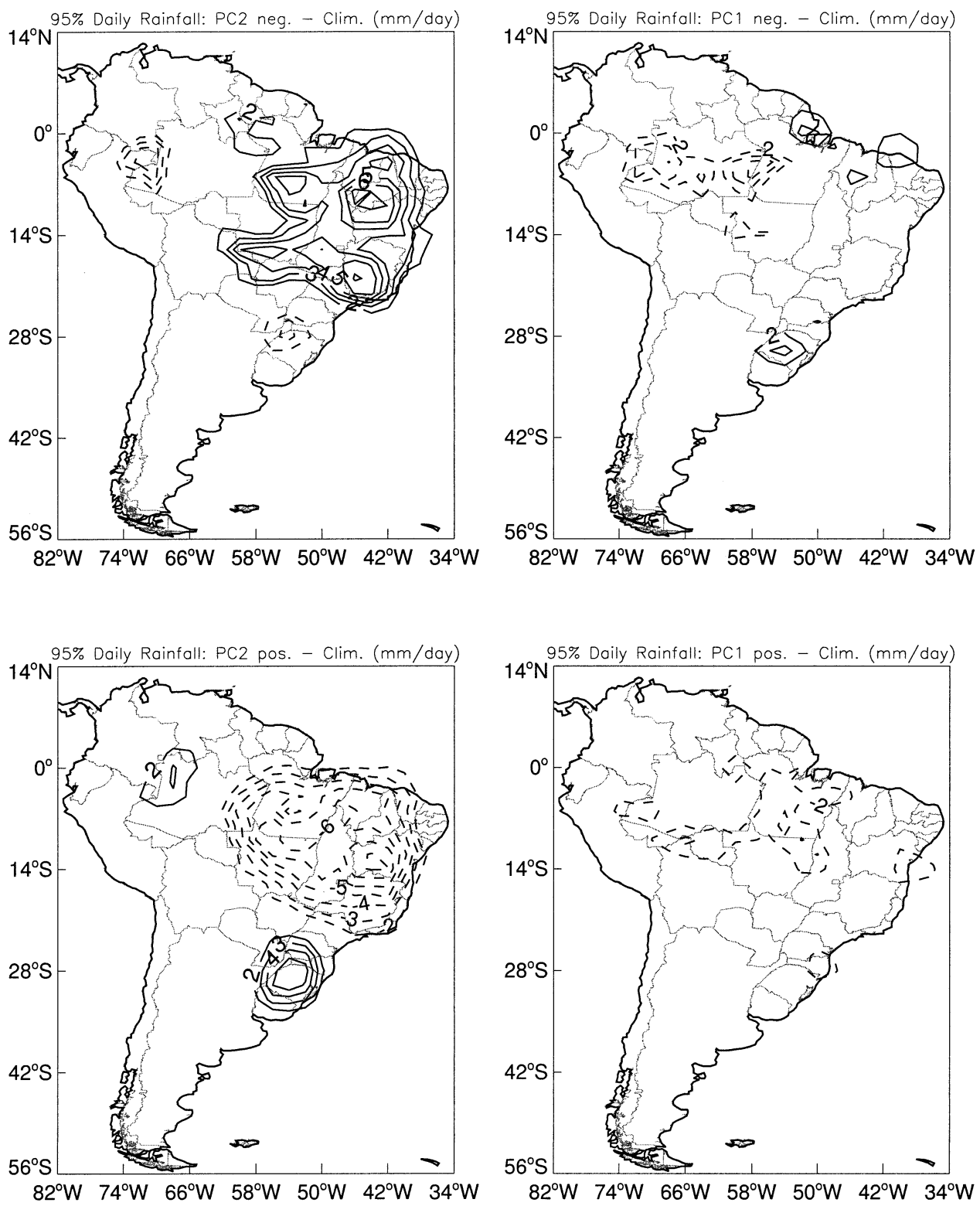

FIG. 17. As in Fig. 16 but for MJO active phases.

SACZ. The increase of the ratio between oceanic and continental categories certainly has an important implication for the regional seasonal total rainfall over south and southeastern South America and central Brazil.

Another important outcome of the present work is the investigation of extreme precipitation over Brazil with respect to SACZ categories and the MJO. This analysis was performed by computing the difference between the 95th percentile daily rainfall obtained from each SACZ category and MJO phase and the DJF climatology. For the sample of intense SACZ, differences of more than $5 \mathrm{~mm}$ day $^{-1}$ in the DJF 95th percentile are observed over central-eastern and southeastern Brazil, where the
DJF 95th percentile is about $25 \mathrm{~mm}$ day $^{-1}$. Conversely, negative differences of more than $7 \mathrm{~mm} \mathrm{day}^{-1}$ are observed in a large area over central and eastern Brazil associated with the weak category. Oceanic SACZ, as expected, increase the DJF 95th rainfall percentile to more than $5 \mathrm{~mm}$ day $^{-1}$ over southeastern Brazil, particularly over the states of Rio de Janeiro, southeastern of Minas Gerais, and northeastern São Paulo (Carvalho et al. 2002), which represents about $20 \%-25 \%$ of the 95th climatology. Stationary oceanic SACZ have been noticed as the cause of frequent states of emergency in these regions due to the increase in floods and mud slides, particularly in areas with steep topography and high concentration of inhabitants. Since warm ENSO 
episodes seem to favor the occurrence of a persistent oceanic SACZ, the correct prediction of the phenomenon brings an additional alert for the occurrence of extreme precipitation over southeastern Brazil, as pointed out in Liebmann et al. (2001) and Carvalho et al. (2002). The decrease of the 95th percentile daily rainfall over the central Amazon basin seems consistent with the decrease of daily mean precipitation when the SACZ is displaced towards the Atlantic Ocean. The continental SACZ shows features very near the climatology for most regions in Brazil, except southeastern Brazil where opposite features to the oceanic SACZ are displayed. Nonetheless, the area with maximum in negative anomalies associated with this category is mostly located in a region with poor and/or intermittent observations, thus not allowing further reliable interpretation of rainfall patterns.

Significant relationships between the MJO and the occurrence of extreme rainfall over Brazil have also been found. Although it is not possible to isolate the effects of the MJO from the SACZ because the former modulates persistence of the latter, some peculiar aspects of the MJO are noticeable. An increase in the 95th percentile daily rainfall of more than $5 \mathrm{~mm} \mathrm{day}^{-1}$ is observed over eastern tropical Brazil, where DJF climatology is between 15 and $20 \mathrm{~mm} \mathrm{day}^{-1}$, in the MJO phase when suppressed convection is observed over Indonesia and enhanced convection over central Pacific. Conversely, the phase of the MJO characterized by enhanced convection over Indonesia and suppression over the central Pacific decreases (increases) the 95th percentile daily rainfall over eastern and southeastern (southern) Brazil. Other phases of the MJO do not seem to modulate the DJF climatology. It is clear, therefore, that monitoring the SACZ, MJO, and ENSO phases can provide significant improvements in the forecast skill of extreme rainfall in tropical South America.

The discussions above raised an important question about the relationships between the broad definition of the SAMS regime and the SACZ. Our results indicate that variability of the SACZ seems mutually related to the SAMS, suggesting that mechanisms responsible for variations in intensity of the former determine the largescale features of the latter. Experienced weather forecasters, in an attempt to identify the SACZ, use satellite images to search for extensive cloud bands from the Amazon southeastward to the Atlantic Ocean (e.g., http://www.cptec.inpe.br/products/climanalise), which is frequently associated with strong convective activity over the continent. Their observations inspired us to define a more appropriate method to describe the SACZ to substitute those that emphasize only the oceanic aspect of the phenomenon. Indeed, some of those experienced meteorologists and forecasters agree that the acronym SACZ should mean South American convergence zone rather than South Atlantic convergence zone. The reason is that, in practice, it is difficult to separate the SACZ activity from the SAMS, unless convective activity is preferably strong over the ocean and weak over central and western Amazon. The methodology presented in this paper objectively identifies these cases.

Acknowledgments. The authors would like to thank the anonymous reviewers for their interesting comments and suggestions. Fruitful discussions with Dr. Pedro L. Silva Dias are appreciated. Datasets were obtained from the National Center for Atmospheric Research (NCAR), which is supported by the National Science Foundation. The rainfall data were provided by ANEEL (Brazil). The support from Dave Allured (CIRES/CDC) is greatly acknowledged. The authors acknowledge the financial support of the CLIVAR PACS Program. L. M. V. Carvalho thanks the financial support from FAPESP (proc: 01-13159-9) and CNPq (proc: 302203/2002-8).

\section{REFERENCES}

Ambrizzi, T., and B. J. Hoskins, 1997: Stationary Rossby-wave propagation in a baroclinic atmosphere. Quart. J. Roy. Meteor. Soc., 123, 919-928.

Barreiro, M., P. Chang, and R. Saravanan, 2002: Variability of the South Atlantic convergence zone simulated by an atmospheric general circulation model. J. Climate, 15, 745-763.

Carvalho, L. M. V., and C. Jones, 2001: A satellite method to identify structural properties of mesoscale convective systems based on maximum spatial correlation tracking technique (MASCOTTE). J. Appl. Meteor., 40, 1683-1701.

__ C. Jones, and B. Liebmann, 2002: Extreme precipitation events in southeastern South America and large-scale convective patterns in the South Atlantic convergence zone. J. Climate, 15, 2377-2394.

Duchon, C. E., 1979: Lanczos filter in one and two dimensions. J. Appl. Meteor., 18, 1016-1022.

Grimm, A. M., 2003: The El Niño impact on the summer monsoon in Brazil: Regional processes versus remote influences. J. Climate, 16, 263-280.

- and P. L. Silva Dias, 1995: Analysis of tropical-extratropical interactions with influence functions of a barotropic model. $J$. Atmos. Sci., 52, 3538-3555.

Hendon, H. H., and M. L. Salby, 1994: The life cycle of the MaddenJulian oscillation. J. Atmos. Sci., 51, 2225-2237.

Hoerling, M. P., and A. Kumar, 2000: Understanding and predicting extratropical teleconnections related to ENSO. El Niño and the Southern Oscillation, H. F. Diaz and V. Markgraf, Eds., Cambridge, 59-88.

Jackson, J. E., 1991: A User's Guide to Principal Components. Wiley, $569 \mathrm{pp}$.

Jones, C., 2000: Occurrence of extreme precipitation events in California and relationships with the Madden-Julian oscillation. $J$. Climate, 13, 3576-3587.

, and L. M. V. Carvalho, 2002: Active and break phases in the South America monsoon system. J. Climate, 15, 905-914.

_ D. E. Waliser, and C. Gautier, 1998: The influence of the Madden-Julian oscillation on ocean surface heat fluxes and sea surface temperature. J. Climate, 11, 1057-1072.

Kalnay, E., and Coauthors, 1996: The NCEP/NCAR 40-Year Reanalysis Project. Bull. Amer. Meteor. Soc., 77, 437-471.

Kiladis, G. N., and K. M. Weickman, 1992: Circulation anomalies associated with tropical convection during northern winter. Mon. Wea. Rev., 120, 1900-1923.

—_, and ——, 1997: Horizontal structure and seasonality of largescale circulations associated with submonthly tropical convection. Mon. Wea. Rev., 125, 1997-2013.

Kodama, Y. M., 1992: Large-scale common features of subtropical 
precipitation zones (the Baiu frontal zone, the SPCZ, and the SACZ). Part I: Characteristics of subtropical frontal zones. $J$. Meteor. Soc. Japan., 70, 813-835.

_ 1993: Large-scale common features of subtropical convergence zones (the Baiu frontal zone, the SPCZ, and the SACZ). Part II: Conditions of the circulations for generating STCZs. J. Meteor. Soc. Japan, 71, 581-610.

Kousky, V. E., and C. F. Ropelewski, 1989: Extremes in Southern Oscillation and their relationship to precipitation anomalies with emphasis on the South American region. Rev. Bras. Meteor., 4, 351-363.

Lenters, J. D., and K. H. Cook, 1999: Summertime precipitation variability over South America: Role of the large-scale circulation. Mon. Wea. Rev., 127, 409-431.

Liebmann, B., and C. Smith, 1996: Description of a complete (interpolated) outgoing longwave radiation. Bull. Amer. Meteor. Soc., 77, 1570-1573.

— , G. N. Kiladis, J. A. Marengo, T. Ambrizzi, and J. D. Glick, 1999: Submonthly convective variability over South America and the South Atlantic convergence zone. J. Climate, 12, 19771991.

_ C. C. Jones, and L. M. V. Carvalho, 2001: Interannual variability of daily extreme precipitation events in the state of São Paulo, Brazil. J. Climate, 14, 208-218.

Madden, R. A., and P. R. Julian, 1994: Observations of the 40-50 day tropical oscillation-A review. Mon. Wea. Rev., 122, 814837.

Maloney, E. D., and D. L. Hartmann, 1998: Frictional moisture convergence in a composite life cycle of the Madden-Julian oscillation. J. Climate, 11, 2387-2403.

Marengo, J. A., and W. R. Soares, 2002: Climatology of low-level jet east of the Andes as derived from the NCEP reanalyses. Preprints, VAMOS/CLIVAR/WCRP Conf. on South American Low-Level Jet, Santa Cruz de la Sierra, Bolivia. [Available online at www-cima.at.fcen.uba.ar/sallj/sallj_conf_extabs.html.]

Nieto-Ferreira, R., T. Rickenbach, D. L. Herdies, and L. M. V. Carvalho, 2003: Variability of South American convective cloud systems and tropospheric circulation during January-March 1998 and 1999. Mon. Wea. Rev., 131, 961-973.

Nogués-Paegle, J., and K. C. Mo, 1997: Alternating wet and dry conditions over South America during summer. Mon. Wea. Rev., 125, 279-291.

—, L. A. Byerle, and K. C. Mo, 2000: Intraseasonal modulation of South American summer precipitation. Mon. Wea. Rev., 128, 837-850.

North, G. R., T. L. Bell, and R. F. Cahalan, 1982: Sampling errors in the estimation of empirical orthogonal functions. Mon. Wea. Rev., 110, 699-706.

Rickenbach, T., R. N. Ferreira, J. Halverson, and M. A. F. Silva Dias, 2002: Modulation of convection in the southwestern Amazon basin by extratropical stationary fronts. J. Geophys. Res., 107, 8040, doi:10.1029/2000JD000263.

Robertson, A. W., and C. R. Mechoso, 2000: Interannual and interdecadal variability of the South Atlantic convergence zone. Mon Wea. Rev., 128, 2947-2957.

Ropelewski, C. F., and M. S. Halpert, 1987: Global and regional scale precipitation patterns associated with the El Niño/Southern Oscillation. Mon. Wea. Rev., 115, 1606-1626.

Satyamurti, P., C. Nobre, and P. L. Silva Dias, 1998: South America. Meteorology of the Southern Hemisphere, D. J. Karoly and D. G. Vincent, Eds., Amer. Meteor. Soc., 119-139.

Zhou, J., and K. M. Lau, 1998: Does a monsoon climate exist over South America? J. Climate, 11, 1020-1040. 